Boletín de la Sociedad Geológica Mexicana

Volumen Conmemorativo del Centenario

Revisión de algunas Tipologías de Depósitos Minerales de México

Tомо LVIII, NÚM. 1, 2006, P. 141-160

\title{
Geología, estructura y composición de los principales yacimientos de carbón mineral en México
}

\author{
Rodolfo Corona-Esquivel ${ }^{1,2^{*}}$, Jordi Tritlla ${ }^{3}$, María Elena Benavides-Muñoz ${ }^{4}$, \\ Noé Piedad-Sánchez ${ }^{5}$, Ismael Ferrusquía-Villafranca ${ }^{1}$ \\ ${ }^{1}$ Instituto de Geología, Universidad Nacional Autónoma de México, Ciudad Universitaria, 04510 México, D.F. \\ ${ }^{2}$ Escuela Superior de Ingeniería y Arquitectura, Instituto Politécnico Nacional. Av. Ticomán No. 600, 07340, México, D.F. \\ ${ }^{3}$ Programa de Geofluidos, Centro de Geociencias, Universidad Nacional Autónoma de México. Campus Juriquilla, A.P. 15, 76230 \\ Santiago de Querétaro, Qro., México \\ ${ }^{4}$ Vid 120, Colonia Nueva Santa María, 02800, México D.F., México \\ ${ }^{5}$ Escuela Superior de Ingeniería "Lic. Adolfo López Mateos", Universidad Autónoma de Coahuila, Blvd. Adolfo López Mateos s/n, \\ 26800, Nueva Rosita, Coahuila, México \\ *rcorona@servidor.unam.mx
}

\section{Resumen}

En México se conocen yacimientos de carbón mineral desde el año 1850. La primera producción comercial de la que se tiene referencia se inició en el año 1884 en el estado de Coahuila. El carbón se utilizó primero para fundir cobre en las minas de Pánuco, Coah, después para proveer de combustible a los ferrocarriles y hacia fines del siglo XIX, para las recientes industrias metalúrgica y del acero.

Los principales yacimientos de carbón se localizan en 3 regiones que, por orden de importancia actual, corresponden a los estados de Coahuila, Oaxaca y Sonora. También se encuentran evidencias de carbón en otros estados de la República: Colima, Chihuahua, Chiapas, Durango, Guerrero, Hidalgo, Jalisco, Nuevo León, Michoacán, Puebla, San Luis Potosí, Tabasco y Veracruz.

La región carbonífera de Coahuila es la más importante del país, se ubica en la porción norte-central del estado de Coahuila y se extiende al oriente hasta incluir una pequeña área del estado de Nuevo León. Esta región, también designada "Cuenca de Sabinas", puede dividirse en dos sub-regiones. La primera se sitúa al sur de Nueva Rosita y de Sabinas, extendiéndose hasta las cercanías de Monclova, y cubre una superficie aproximada de $10,000 \mathrm{~km}^{2}$. La segunda se localiza en el área de Nava-Piedras Negras, se extiende en una franja paralela al Río Bravo del Norte cubriendo una superficie de aproximadamente $2,000 \mathrm{~km}^{2}$ y se le designa como "Zona de Fuentes-Río Escondido".

Las rocas que afloran dentro de la Región Carbonífera de Coahuila varían en edad del Jurásico Tardío al Cuaternario, y se estructuran bajo la forma de anticlinales y sinclinales de dimensiones relativamente grandes. El carbón de estas subcuencas es de tipo sub-bituminoso apropiado para su transformación en coque, tiene volatilidad media a baja, presenta preponderanteménte vitrinita como constituyente con un poder reflector de 0.6-1.2 \%. Las reservas estimadas de carbón en estas subcuencas es de unos 1,200 millones de toneladas.

La Región de Mixtepec-El Consuelo-Tezoatlán se localiza en la porción noroccidental del estado de Oaxaca y se extiende hacia los vecinos estados de Puebla y de Guerrero. Los mantos de carbón se encuentran en la parte inferior de las Formaciones Rosario, Zorillo y Simón del Jurásico Medio, constituidas por una alternancia de areniscas, lutitas y limolitas, depositadas probablemente en un ambiente deltaico. El espesor de las capas de carbón varía de unos cuantos centímetros hasta $3 \mathrm{~m}$. Se estima que esa área contiene un tonelaje mayor a los 30 millones de toneladas de carbón. 
El carbón de Sonora, se localiza aproximadamente a $90 \mathrm{~km}$ al sur de Hermosillo. La unidad portadora, tanto de los mantos de carbón como del grafito, es la Formación Barranca del Triásico, constituida por conglomerados, areniscas y limolitas rojas con intercalaciones de lutitas y mantos de carbón y grafito. Las reservas de carbón en el estado son del orden de los 85 millones de toneladas estimadas.

Palabras claves: Carbón, yacimientos, características, México.

\begin{abstract}
Coal deposits in Mexico were firtsly recognized back in 1850; the first commercial production started around 1884 in Coahuila State. The coal was used primarily for copper smelting at the mines of Pánuco, Coahuila. Later, it was used as ferrocarril fuel and, at the end of the $19^{\text {th }}$ century, for the metallurgical and steel plants.

In order of importance the main coal deposits are located within the States of Coahuila, Oaxaca and Sonora. Small, subeconomical or poorly explored coal occurrences are known to occur in the States of Colima, Chihuahua, Chiapas, Durango, Guerrero, Hidalgo, Jalisco, Nuevo León, Michoacán, Puebla, San Luís Potosí, Tabasco and Veracruz.

The main coal deposits in Mexico are located north of the Coahuila State, affecting a small portion of the Nuevo Leon State. The coal seams are found exclusively in the sedimentary sequence of the Sabinas Basin, that can be subsequently dividied into two different sub-regions. The first sub-region spans between of Nueva Rosita and Sabinas up to Monclova, covering an area of approximately 10,000 km². The second sub-region, known as the "Fuentes-Rio Escondido Zone", is located in the Nava-Piedras Negras area, parallel to the Rio Bravo del Norte, within an area of 2,000 $\mathrm{km}^{2}$.

The sedimentary sequence that contains the coal seams in the Sabinas Basin range from the Late Jurassic to the Quaternary, structured as a series of broad anticlines and synclines. Coal reserves are stimated at 1,200 million tons including both sub-bituminous coal, to be transfomed in coke, and high volatility " $C$ " sub-bituminous coal, used in electrical power plants.

The Mixtepec coal region, including El Consuelo-Tezoatlán, is located in the northwestern portion of the Oaxaca state, partially including the neighboring states of Puebla and Guerrero. The coal seams appear at lower part of the Rosario, Zorillo and Simon Formations of Jurassic age. They are made up by a succession of sandstones, shales and silt representing a deltaic sedimentary environment. The thickness of the coal horizons is variable, between few centimeters up to $3 \mathrm{~m}$. This zone has been evaluated to contain around 30 million tons of coal.

The coal in the Sonora State is located approximately $90 \mathrm{~km}$ south of Hermosillo. The Barranca Formation (Triassic) is the coal and graphite-bearing unit, and it is made up by the succession of red conglomerates, sandstones and siltstones interbeded with shales and coal seams and graphite. The calculated coal reserves are around 85 million proven tons.
\end{abstract}

Keys words: Coal, deposits, characteristics, Mexico.

\section{Introducción}

El carbón ha sido y aún continua siendo uno de los recursos energéticos no renovables más apreciados por la humanidad. A partir de la revolución industrial, la exploración y explotación de los yacimientos de carbón ha incidido en la evolución y modernización de la sociedad, pasando de ser prácticamente la única fuente de energía a un complemento de los hidrocarburos utilizados en la generación de electricidad (Laherrère, 2000; Tissot, 2001). La crisis anunciada desde hace años tanto en la calidad como en la cantidad de petróleo, hace que el carbón gane otra vez importancia en el desarrollo del país. En consecuencia, resulta oportuno revisar el conocimiento que se tiene actualmente sobre la geología y características de los yacimientos de este recurso.

Como parte de los eventos organizados para conmemorar los 100 años de la fundación de la Sociedad Geológica
Mexicana, presentamos este trabajo. En la primera parte se realiza una sucinta revisión sobre la génesis de los depósitos carboníferos; en la segunda, se realiza una descripción de los principales yacimientos de carbón en México.

\section{Génesis de los yacimientos de carbón}

Generalmente se define al carbón como una roca de origen orgánico que se genera por la diagénesis, a cierta presión y temperatura, de materia vegetal procedente de pteridofitas, gimnospermas y angiospermas. La composición del carbón incluye carbono, hidrógeno, oxígeno, así como pequeñas cantidades de azufre y nitrógeno; contiene además, dióxido de carbono y metano; compuestos aceitosos, como alquitrán y brea, que a su vez contienen amoniaco, tolueno, naftas y creosotas (Diessel, 1986, 1992; Philp, 1994; Clayton, 1998; Chen y Ma, 2002; Wilkins y 
George, 2002). La mayoría de los yacimientos de carbón mineral se generan en paleoambientes pantanosos asociados a lagunas, deltas o estuarios.

La formación de yacimientos económicamente explotables ocurre cuando se cumplen las siguientes cuatro condiciones:

1. Presencia de vegetación muy abundante, normalmente en un ambiente tropical, cálido y húmedo.

2. Ambiente tectónico de subsidencia balanceado con el crecimiento y sepultamiento de la vegetación.

3. El sepultamiento de la vegetación muerta debe ser rápido, de tal manera que ésta no quede expuesta a la oxidación en la superficie. Bajo estas condiciones, la descomposición de la materia orgánica sepultada ocurre muy lentamente o no sucede, permitiendo que se forme la turba.

4. Todas las condiciones anteriores deben presentarse juntas durante intervalos de tiempo prolongados, alternados con lapsos durante los que se depositen otro tipo de sedimentos.

La acumulación de turba se lleva a cabo in situ, en el propio medio de vida de las plantas como deltas, estuarios o albuferas y, muy pocas veces, por transporte en medios distintos al de formación. Estas características permiten diferenciar los carbones autóctonos, formados en el propio ecosistema, y los carbones alóctonos, formados en un medio diferente al ecosistema original, por lo que la materia vegetal ha sufrido un transporte más o menos largo. Según el medio de formación, también es posible diferenciar entre los carbones hímnicos, formados en medios lacustres, y parálicos, formados en ambientes transicionales como deltas, estuarios o lagunas (Águeda et al., 1991; Calder et al., 1991; Diessel, 1992; van Krevelen, 1993; PiedadSánchez, 2005).

Así, los medios más propicios en los que pueden darse procesos de acumulación de materia vegetal son:

- Lagunas, estuarios y marismas, saladas o salobres. Éstas son zonas con comunicación ocasional con el mar, en las que se produce una importante actividad biológica vegetal.

- Zonas pantanosas, ciénagas, canales, lagos y charcas intracontinentales, con vegetación de tipos diversos (herbácea o leñosa) controlada por la profundidad del medio, sus condiciones del fondo, temperatura de las aguas, etc.

- Manglares de las zonas tropicales que se encuentran bordeando a las lagunas y a los estuarios.

- Ambientes fluviales y deltaicos.

Un factor también importante es el clima (paleoclima) imperante durante la época de formación del carbón. Los más favorables son los paleoclimas tropicales, generadores de vegetación exuberante. Asimismo, es importante considerar la edad de las series sedimentarias en las que aparece, ya que las plantas vasculares aparecieron en el Silúrico, y poblaron la mayor parte de la superficie de la Tierra durante el Devónico, originándose entonces los depósitos de carbón más antiguos conocidos. Posteriormente, se formaron yacimientos de carbón prácticamente de todas las edades, aunque existen períodos especialmente favorables que se explican por factores fundamentalmente tectónicos, paleoclimáticos y de tipo de vegetación predominante en cada uno de dichos períodos (Águeda et al., 1991; Calder et al., 1991; Diessel, 1992; van Krevelen, 1993; PiedadSánchez, 2005).

El carbón es una roca sedimentaria organoclástica de grano fino, compuesta esencialmente por restos carbonizados de plantas. Estas rocas organoclásticas suelen constituir secuencias estratigráficas características que reciben el nombre de ciclotema, es decir, una secuencia litológica que se repite en el tiempo.

Los ciclotemas están típicamente consituídos, de la base a la cima, por capas de: (1) arcillas (lacustres o marinas); (2) areniscas y limolitas; (3) conglomerados; y (4) carbón. Aunque no todos los ciclotemas contienen yacimientos de carbón económicamente explotables, el estudio de estas secuencias ha llevado a un mejor entendimiento de la formación de tales yacimientos (Prothero y Schwab, 1996). Gracias precisamente a esta estructura estratigráfica, con frecuencia el carbón forma mantos de gran extensión, cuyo espesor varía desde pocos milímetros hasta varios metros. En otros casos, los estratos de carbón aparecen intercalados aleatoriamente con areniscas, limolitas, margas o calizas. Es de destacar que la zona de transición continental/marina constituye el ambiente sedimentario más frecuentemente asociado a la génesis de yacimientos de carbón.

En el ciclotema representado en la Figura 1, la secuencia estratigráfica se inicia con tres capas de rocas sedimentarias no marinas. El miembro 1 corresponde a una unidad de arenisca que descansa discordantemente sobre las capas que subyacen al ciclotema. Esta capa de arenisca está cubierta por estratos de lutita (miembro 2 ) y caliza lacustre (miembro 3). El miembro 4 suele ser un paleosuelo gris con fragmentos de raíces, que siempre subyace al manto de carbón (miembro 5). Una serie de 5 unidades sobreyacen al carbón; su composición incluye lutitas arcillosas (Miembro 6), calizas marinas (Miembro 7), lutitas (Miembro 8), calizas marinas (Miembro 9) y, finalmente, lutitas arcillosas (Miembro 10). Esta última unidad está truncada por una superficie de erosión, que forma la base del ciclotema suprayacente. Así, es posible reconstruir la sucesión de ambientes sedimentarios: los miembros no marinos $(1,2,3)$ se intercalaron con arenas fluvio-deltaicas y lodos, junto con limos y calizas lacustres; el miembro 4 representaría el suelo en el cual creció la gruesa cubierta vegetal cercana a la costa en un complejo pantanoso sobre la planicie costera laguna o delta; el miembro 5, el estrato de carbón, se formó cuando la transgresión marina inundó la masa vegetal, sepultándola rápidamente. La acción de las bacterias junto con el sepultamiento y la compactación de este material turboso, generó carbón bituminoso, el cual mediante metamorfismo, pudo haberse transformado en antracita.

La destrucción del complejo pantano-bosque de estuario 


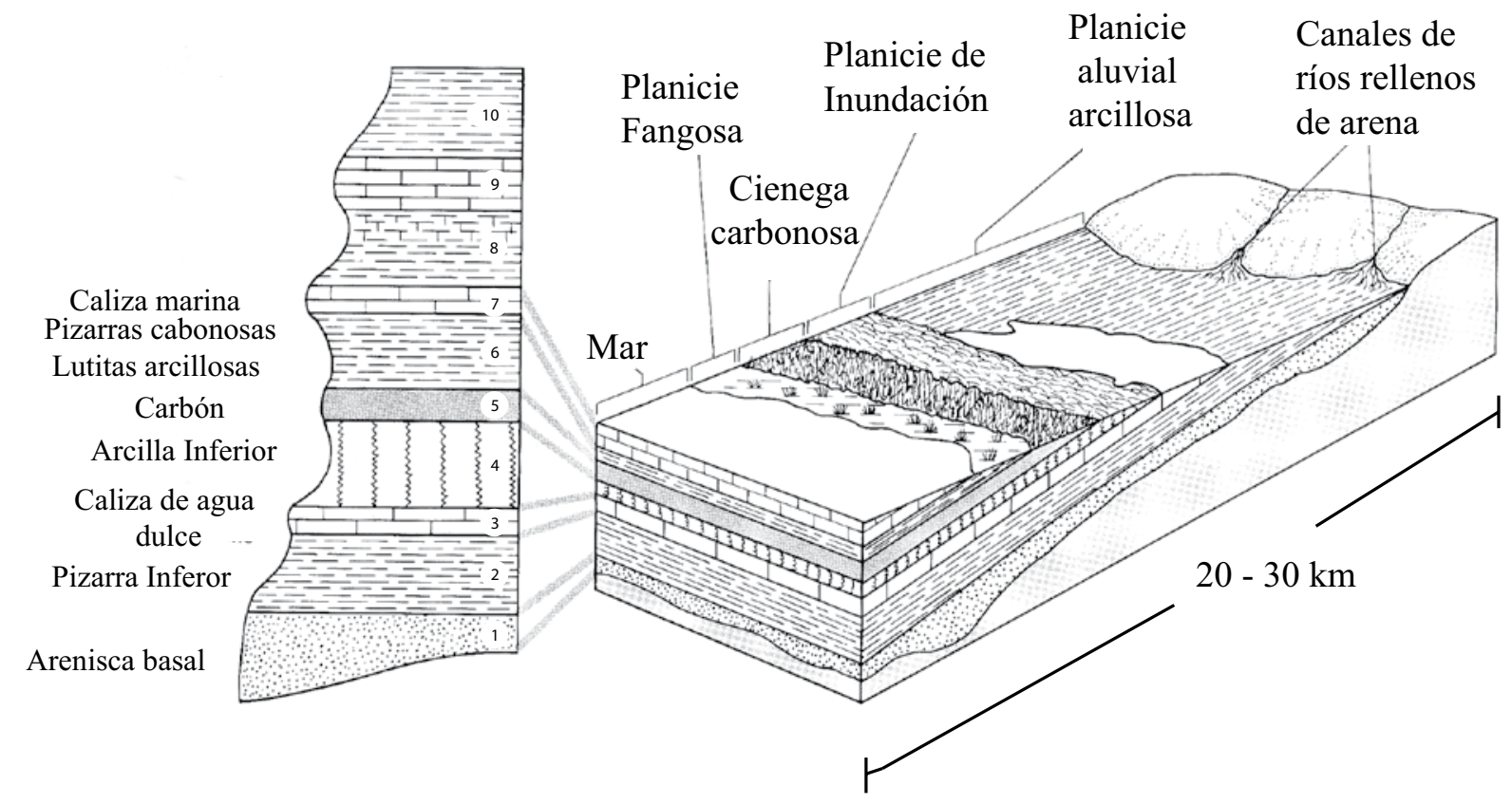

Figura 1. Modelo tradicional que muestra a los ciclotemas y depósitos pensilvánicos de carbón de la Cuenca de Illinois, EUA (Shaw, in Prothero y Schwab, 1977).

o delta fue causada por una transgresión marina abrupta (miembros 6 al 10). La porción superior marina del ciclotema (miembro 10), registra una nueva regresión que está marcada por la presencia de una superficie de erosión que indica el subsiguiente descenso del nivel del mar, hecho que provoca la formación de una región costera y el restablecimiento de los ambientes y vegetación. Los ciclotemas no necesariamente se ajustan a esta secuencia o patrón idealizado de diez miembros, lo cual puede indicar que los cambios del nivel del mar ocurrieron más rápidamente, o bien, que algún proceso interrumpió la secuencia habitual de eventos.

La mayoría de los ciclotemas con carbón se extienden a través de grandes regiones continentales formando series, aunque raramente pueden también presentarse aislados. En algunas áreas se han reconocido series de hasta 10 ciclotemas (Prothero y Schwab, 1996). En Norteamérica, los ciclotemas portadores de carbón se extienden por miles de kilómetros cuadrados, son notablemente uniformes en espesor y en organización interna. Durante el Carbonífero, gran parte de Norte América Oriental era una enorme planicie que yacía casi al nivel del mar, similar a la actual planicie costera del Golfo de México. El apilamiento de estos ciclotemas carboníferos indica frecuentes y repetidos ascensos y descensos del nivel del mar. (Prothero y Schwab, 1996).

Otro de los ambientes sedimentarios favorables para la formación de yacimientos de carbón es el deltaico. La distribución, orientación y arquitectura de los deltas depende de varios factores, como son el clima, el caudal del río y la dinámica de éste en la desembocadura, aporte de sedimentos, el oleaje, los vientos, así como la pendiente, configuración y "movilidad tectónica" de la cuenca de depósito. Por lo general, los sedimentos deltaicos presentan grandes espesores (varios cientos de metros), principalmente de areniscas y/o limolitas. Las capas de carbón que se forman en estos ambientes suelen contener fauna en las unidades inter-estratificadas que pueden indicar ambientes de aguas marinas o continentales que, junto con las estructuras sedimentarias, sugieren unas condiciones de depósito en aguas poco profundas (Águeda et al., 1991; Calder et al., 1991; Diessel, 1992; Prothero y Schwab, 1996).

La investigación y la experimentación continúan en el dominio de la tecnología de exploración y producción, con el objetivo adicional de extraer el gas natural de los yacimientos de carbón (metano de hulla o "gas grisú"). El carbón contiene en proporción más o menos significativa materia volátil compuesta esencialmente por hidrógeno y metano, aunque también puede contener compuestos complejos. La desorpción de esta materia volátil puede volumétricamente alcanzar más de $100 \mathrm{~m}^{3}$ de gas por tonelada de carbón extraído (Boden y Ehrlich, 1998; Bustin y Clarkson, 1998; Crosdale et al., 1998; Flores, 1998; Laxminarayana y Crosdale, 1999; Krooss et al., 2002). El gas de las minas es prácticamente idéntico al gas natural en su composición por lo que puede ser y es utilizado como combustible. El contenido y la composición química del gas grisú es variable y consiste principalmente de metano $\left(\mathrm{CH}_{4}\right)$, con cantidades menores de dióxido de carbono $\left(\mathrm{CO}_{2}\right)$, nitrógeno $\left(\mathrm{N}_{2}\right)$, oxígeno $\left(\mathrm{O}_{2}\right)$, agua $\left(\mathrm{H}_{2} \mathrm{O}\right)$, ácido sulfhídrico $\left(\mathrm{H}_{2} \mathrm{~S}\right)$ y otros hidrocarburos (Querol, 2005). 
Desde el punto de vista energético, el aprovechamiento del gas metano de las minas de carbón es una realidad desde hace más de medio siglo. Desde el siglo XIX se inició la desgasificación de las minas de carbón en Inglaterra y el gas obtenido se utilizaba para iluminar la ciudad de Londres. En 1931 se perforó el primer pozo para extraer gas grisú en West Virginia, EE.UU. En Alemania, desde 1950 se inició la construcción de gasoductos para transportar el gas grisú, siendo su uso principalmente para la energía térmica y eléctrica (Querol, 2005). Un ejemplo de exploración para este recurso natural es Francia, un país con una muy escasa producción de gas natural "clásico" y que tiene sus principales minas de carbón cerradas, por lo que está evaluando la posibilidad de descubrir nuevas fuentes de gas para cubrir su consumo interno (Laherrère, 2000).

Recientemente, se ha demostrado que la cantidad de hidrocarburos generados por un carbón dado varía con su composición maceral y su grado de maduración (metamorfismo), y que el aceite generado se transforma en gas por cracking secundario en la microestructura molecular de los macerales del carbón. (Mukhopadhyay y Hatcher, 1993). Asimismo, se conoce que cada compuesto orgánico o maceral (liptinita, vitrinita e inertinita) juega un papel diferente en la generación y el transporte de los hidrocarburos en el carbón (Figura 2; Mukhopadhyay y Hatcher, 1993). Así, la liptinita y algunos macerales de la vitrinita (los más hidrogenados) son responsables de la generación de los hidrocarburos en el carbón. La inertinita no genera hidrocarburos pero puede ser considerada como una verdadera "autopista" para la circulación de los fluidos generados por los otros macerales. Además, las propiedades físicas y químicas de los macerales varían con el grado de metamorfismo en función de las pérdidas de hidrógeno y de oxígeno debidas a la maduración térmica. En función del grado de maduración de un carbón, los hidrocarburos

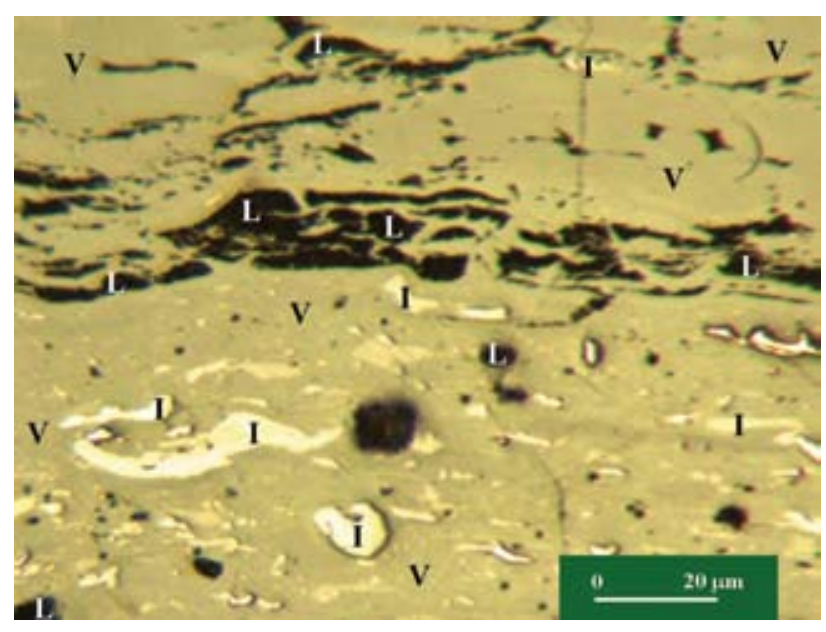

Figura 2. Microfotografía del carbón de la Formación Olmos en el área de Palaú, Coah.: Vitrinita (V) con cavidades celulares en cuyo interior contiene liptinita (L, exudatinita) e Inertinita porosa (I). Luz blanca reflejada. generados van a ser líquidos o gaseosos y la porosidad y la permeabilidad molecular o física de los macerales va a cambiar. En estos intervalos de evolución térmica, la fisuración va a desarrollarse siguiendo la composición química de los macerales y su capacidad de absorción o de desorpción de gas (Bodden y Ehrlich, 1998; Bustin y Clarkson, 1998; Crosdale et al., 1998; Flores, 1998; Laxminarayana y Crosdale, 1999; Krooss et al., 2002).

Por todo ello, la caracterización de los diferentes depósitos de carbón servirá para los estudios de exploración por gas y petróleo, principalmente para dilucidar aspectos sobre la generación, migración y cinética de los hidrocarburos generados en el carbón.

\section{Yacimientos de carbón mineral en México}

\subsection{Antecedentes}

En México se conoce el carbón mineral como un recurso económicamente rentable desde 1850, cuando Birkinbine publicó algunos datos sobre el hierro y carbón de Oaxaca, descubiertos por José V. Camacho (Jiménez, 1921).

La primera producción comercial de la que se tiene referencia se inició en el año 1884, en un socavón excavado cerca del pueblo de San Felipe, al sur de la Estación Sabinas, Coahuila. El carbón se utilizó primero para fundir cobre en las minas de Pánuco (al SW de la Estación Candela, Coahuila), después para proveer de combustible a los ferrocarriles y hacia finales del Siglo XIX, para las nacientes industrias metalúrgicas y del acero. Cabe destacar que la primera exploración sistemática la realizó en 1860 el Ing. Jacobo Küchler, cuando presentó la primera descripción fisiográfica y geográfica, del área de San Felipe El Hondo, población cercana a Sabinas, Coahuila (Salas y Benavides, 1976).

Durante el período de 1910-1930, el carbón fue desplazado por el uso del petróleo, sin embargo, siguió siendo un factor indispensable en la industria siderúrgica y minerometalúrgica, originando un sólido mercado interno. Durante esta época, los subproductos de los materiales volátiles fueron desaprovechados. A partir de $1930 \mathrm{y}$ hasta 1959 la explotación del carbón fue esencial para el desarrollo cada vez más estable de las industrias impulsadas desde 1910, contrastando con la forma muy limitada en que fue aprovechado para la generación de energía eléctrica. Se estima que por esos años el porcentaje máximo utilizado en este servicio no sobrepasaba a las 250,000 ton/año. En este mismo período se establecieron las primeras plantas para obtener los subproductos de los materiales volátiles del carbón (Salas y Benavides, 1976).

Las estadísticas muestran que de 1902 a 1910 se produjeron 10.08 millones de toneladas de carbón "todo uno". De 1911 a 1921 la producción bajó a 3.97 millones de toneladas debido a la Revolución. De 1921 a 1940, época en que proliferaron las compañías carboníferas pequeñas y 
se iniciaron algunas mayores, la producción acumulada fue de 31.99 millones de toneladas de carbón "todo uno", casi todo coquizable, y procedió de las llamadas Subcuencas de Sabinas, Esperanza y otras, en el Estado de Coahuila (Salas y Benavides, 1976).

A partir de 1954 se instalaron en el país plantas coquizadoras de capacidad suficiente para recuperar hasta el 85\% de los subproductos de carbón. En 1959 se instaló en Monclova, Coah., la primera planta de fertilizantes que utilizó gas de la coquizadora construida por Mexicana de Coque y Derivados S.A. de C.V. con una capacidad de 560,000 ton/año (Piedad-Sánchez, 2005).

En décadas posteriores, el rápido desarrollo tanto de la industria siderúrgica como el de la minero-metalúrgica, originaron un sólido mercado interno. Hasta 1940 se habían producido 33.39 millones de toneladas de carbón "todo uno". Para 1972 la producción se incrementó a un total de 89.7 millones de toneladas de carbón del mismo tipo (Salas y Benavides, 1976).

La industria del carbón en nuestro país es primordial como generadora de empleos, inversiones y de electricidad con costos bajos. Sin embargo, la participación de México con respecto a los países más importantes en la exportación del carbón hacia Estados Unidos de América (el principal mercado mundial) es nula, no pudiendo competir con Japón, China y Canadá, en los últimos años (Gobierno del Estado de Coahuila, 2003; Piedad-Sánchez, 2005).

De acuerdo a la Dirección General de Minas de la Secretaría de Economía, la Región Carbonífera de Sabinas sigue detentando el primer lugar en el país en la producción de carbón al finalizar el año 2004, con un estimado de 11'305,022.50 toneladas, señalándose que Coahuila registró un valor de la producción minera para el año 2003 de 2,293'050,400 millones de pesos para el carbón (Gobierno del Estado de Coahuila, 2005; Piedad-Sánchez, 2005).

\subsection{Localización y geología de las cuencas carboníferas}

Si bien se conoce la presencia de indicios de carbón mineral en varios estados de la República Mexicana, los principales yacimientos de este recurso natural se localizan en 3 regiones que, citadas en orden de importancia actual, corresponden a los estados de Coahuila, Oaxaca y Sonora. En otros estados de la República (Colima, Chihuahua, Chiapas, Durango, Guerrero, Hidalgo, Jalisco, Nuevo León, Michoacán, Puebla, San Luis Potosí, Tabasco y Veracruz) también se encuentran evidencias de carbón (Figura 3), aunque siempre de menor importancia económica.

Actualmente, el mayor conocimiento tanto geológico como económico se tiene en las Subcuencas del Distrito Monclova-Sabinas del Estado de Coahuila, las Subcuencas en el Distrito Tezoatlán-Mixtepec, Oaxaca, y las de San Javier-San Marcial en la Cuenca de Barrancas, Sonora.

\subsubsection{Región Carbonífera de Coahuila}

La Región Carbonífera de Coahuila es la más importante del país, aportando más del $90 \%$ de la producción nacional de carbón, de acuerdo a las últimas cifras indi-

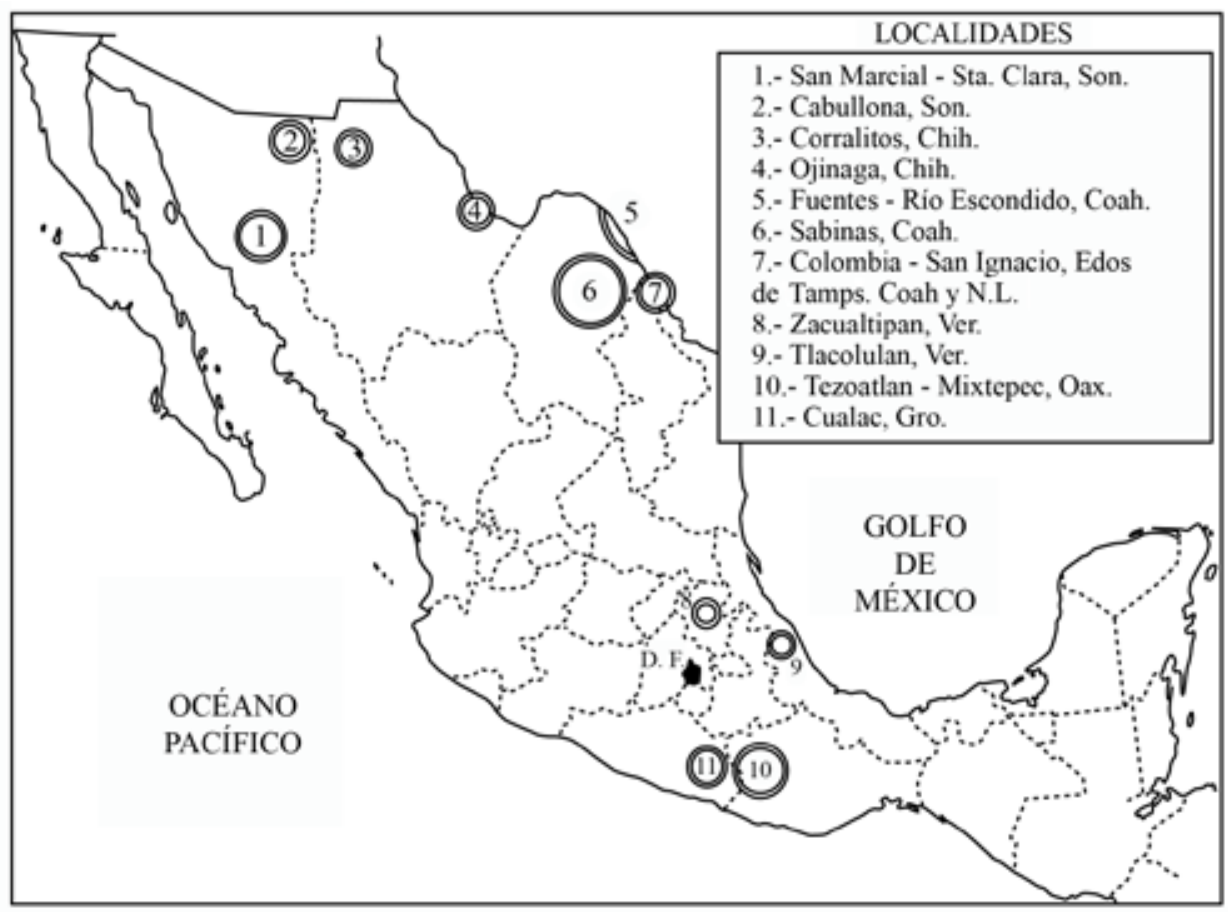

Figura 3. Localización esquemática de las cuencas carboníferas de México (Modificado de Salas y Benavides, 1976). 
cadas por el Consejo de Recursos Minerales (2003). Esta región se ubica en la porción norte-central del Estado de Coahuila y se extiende al oriente hasta incluir una pequeña área del Estado de Nuevo León (Figura 4 ; Robeck et al., 1956, 1960; Flores-Galicia, 1988; Flores-Espinoza, 1989; Brizuela, 1992).

Dumble (1892) y Vaughan (1900) realizaron los primeros estudios geológicos, describiendo las formaciones de la región. Böse y Cavins (1927), con base a la biogeocronología europea, asignaron edad a estas unidades. Finalmente, Stephenson (1927) definió las formaciones tal y como se conocen hasta ahora. El estudio geológico más completo es el de Robeck et al. (1956), en el que se describe detalladamente la estratigrafía y estructura de la región de Sabinas, y se estiman las reservas de carbón. Otros trabajos más recientes han sido publicados por Flores-Galicia (1988), Consejo de Recursos Minerales (1994) y Rivera-Martínez y Alcocer-Valdés (2003), quienes han actualizado el cálculo de reservas.

La Región Carbonífera de Coahuila, también designada "Cuenca de Sabinas", aunque tal y como se ha indicado anteriormente, comprende una cierta parte del territorio de Nuevo León, se divide en dos sub-regiones. La primera se localiza al sur de las poblaciones de Nueva Rosita y de
Sabinas, y se extiende hasta las cercanías de Monclova (Figura 5), cubriendo una superficie aproximadamente de $10,000 \mathrm{~km}^{2}$. La segunda se localiza en el área Nava-Piedras Negras, se extiende en una franja paralela al Río Bravo del Norte, cubre una superficie de aproximadamente $2,000 \mathrm{~km}^{2}$ y se le designa "Zona de Fuentes-Río Escondido", nombre tomado de una pequeña mina del área. (Robeck et al., 1956, 1960; López-Ramos, 1985; Flores-Galicia, 1988; Verdugo y Ariciaga, 1988a, b; Flores-Espinoza, 1989; SantamaríaOrozco, 1990; Brizuela, 1992).

Geológicamente, la "Cuenca de Sabinas" está constituida por ocho "subcuencas" que se corresponden con sinclinales amplios, cuya orientación NW-SE se ajusta a la estructura regional. Estas "subcuencas" localmente se designan como Sabinas, Esperanzas, Saltillito, Lampacitos, San Patricio, Las Adjuntas, Monclova y San Salvador (Flores-Galicia, 1988) (Figura 5).

Las rocas que afloran dentro de la Región Carbonífera de Coahuila varían en edad del Jurásico Tardío al Cuaternario (Young, 1972, 1983; Flores-Galicia, 1988; SantamaríaOrozco, 1990; Eguiluz de Antuñano, 2001; Román-Ramos y Holguín-Quiñones, 2001). Los materiales mesozoicos están esencialmente representados por rocas sedimentarias de ambientes marinos; los sedimentos del Terciario y

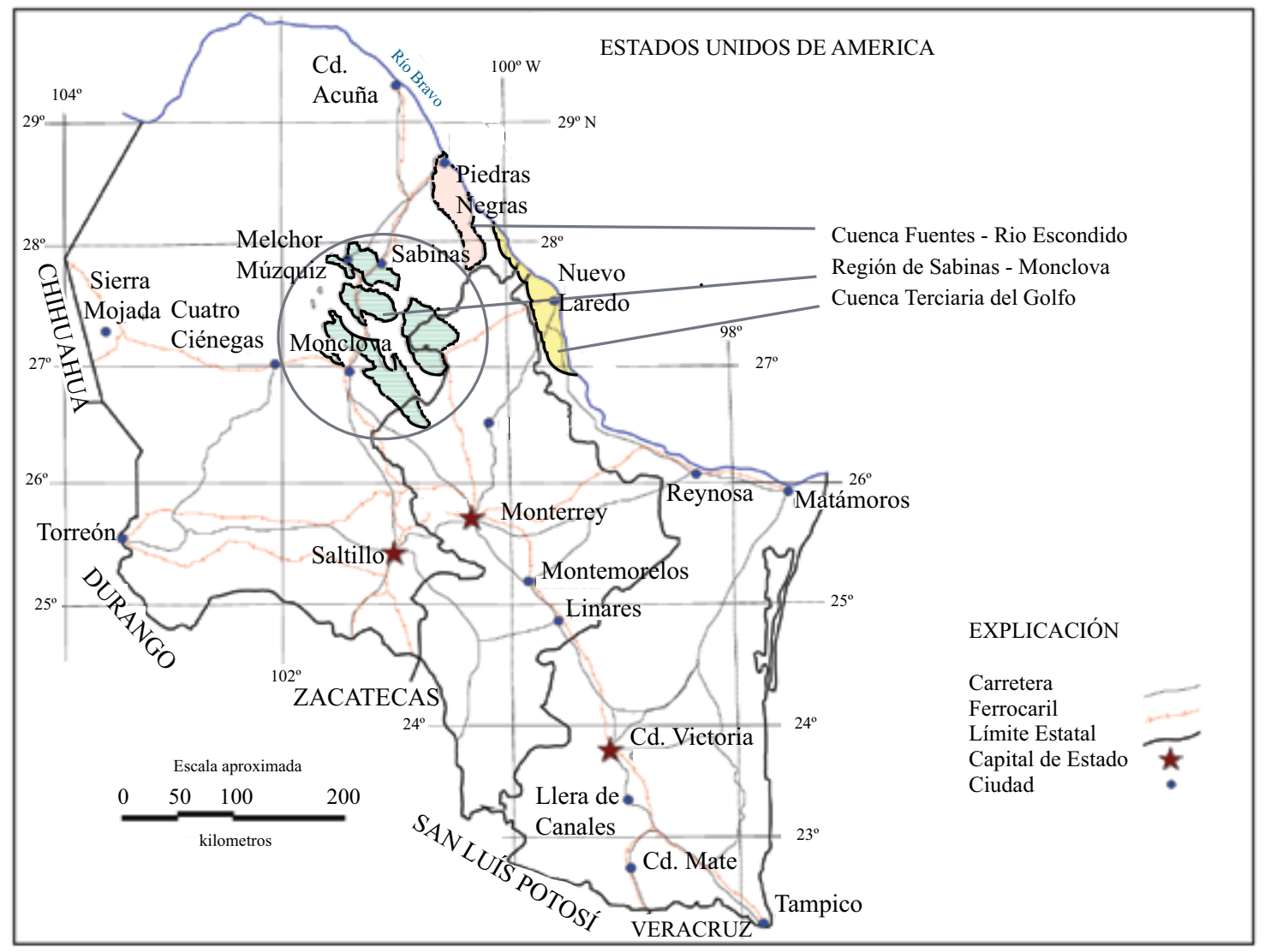

Figura 4. Plano de localización de las cuencas carboníferas de los estados de Coahuila, Nuevo León y Tamaulipas (Tomado de Rivera-Martínez y Alcocer-Valdés 2003). 


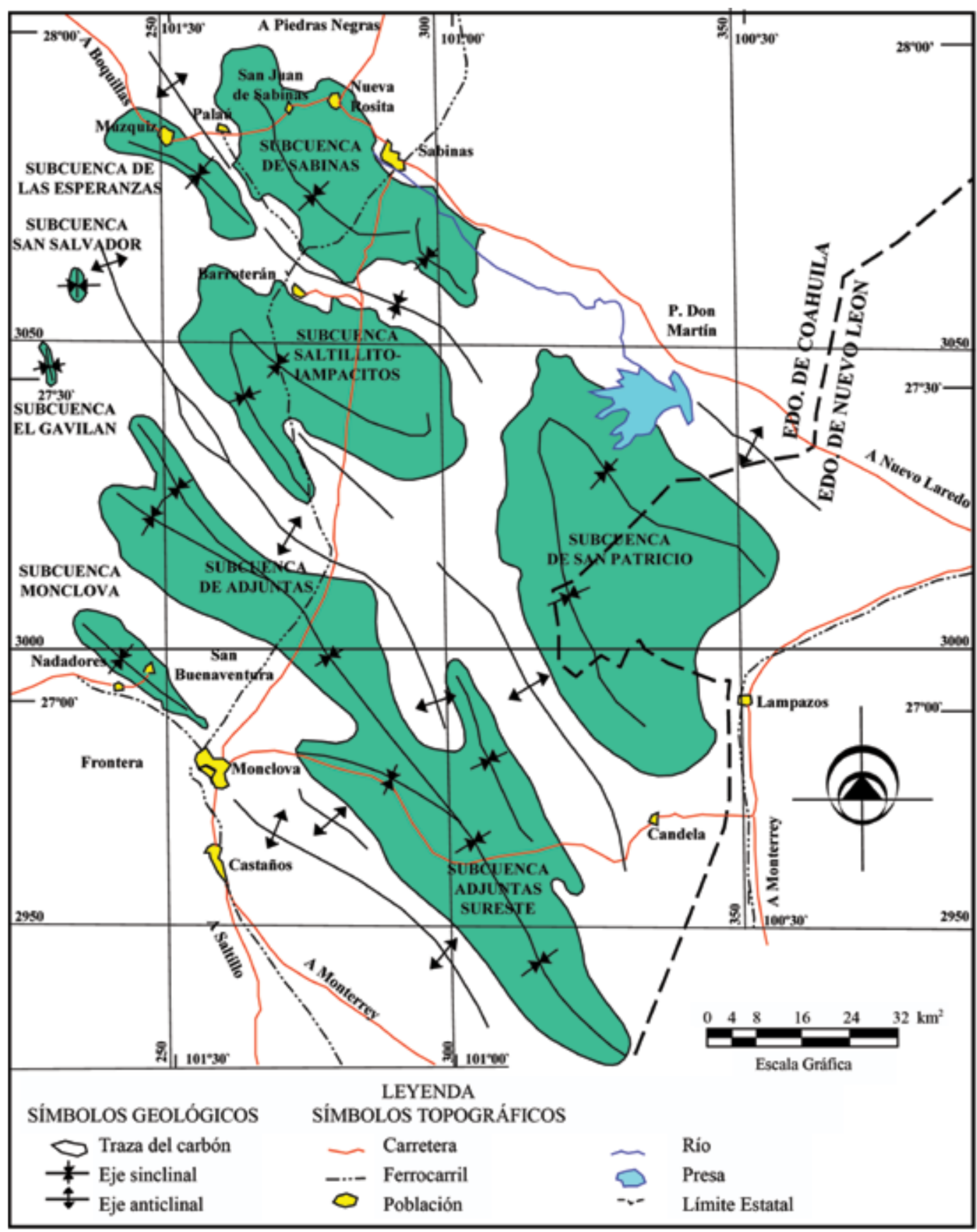

Figura 5. Plano de localización de la Cuenca Sabinas-Monclova (Tomado de Rivera-Martínez y Alcocer-Valdés 2003).

Cuaternario están esencialmente representados por rocas de tipo continental, incluyendo algunos derrames de basalto. Estas rocas han sido estudiadas por varios autores, entre ellos Robeck et al. $(1956,1960)$, de quien se transcribe parte de sus descripciones.

Formación La Casita. Aflora en el Potrero de Ovallos, la Sierra Azul y el Potrero de Menchaca en el Estado de Coahuila. Definida por Imlay (1937) consiste principalmente de pelitas marinas, yeso y carbón. Este último se localiza inmediatamente por debajo de las capas que contienen amonitas del Kimmeridgiano medio. Robeck et al. (1960) mencionan que aunque se realizaron algunas catas en busca del carbón, se hace necesaria una exploración más amplia para poder hacer una estimación adecuada de la cantidad de mineral que pueda haber.

Caliza Menchaca. Su localidad tipo esta en el Potrero de Menchaca, aunque también queda bien expuesta en el Potrero de Ovallos (Robeck et al., 1956). La Formación está compuesta por estratos delgados de caliza gris oscura, que toma color gris claro por intemperismo. En la sección tipo 
se han encontrado ejemplares de Exogyra reedi Imlay y $E$. putnami Imlay. En la sección de Ovallos, se encontraron Neocomites sp., Acanthodiscus y Kilianella, amonitas de edad Valanginiano.

Lutita Barril Viejo. Queda bien expuesta en el Potrero de Ovallos con unos $400 \mathrm{~m}$ de espesor. La formación consiste de limolitas intercaladas con algunos estratos delgados de calizas arenosas que, en conjunto, tienden a adquirir color parduzco por intemperismo. En la parte media de la formación se encontraron ejemplares de amonitas del género Leopoldia y Valanginites, evidencia de que la edad de esa parte de la formación es del final del Valanginiano o del principio del Hauteriviano (Robeck et al., 1956, 1960).

Caliza Padilla. Está bien expuesta en el Potrero de Ovallos, aunque también se la encuentra en el Cañón de La Alameda y la Sierra Azul. Litológicamente consiste en una caliza gris con rudistas, que por lo general forma escarpes. Su edad se considera Barremiana, de acuerdo a su posición estratigráfica (Robeck et al., 1956).

Lutita La Mula. Esta formación está bien expuesta en el Potrero de Ovallos, Cañón de la Alameda y en la Sierra de Santa Rosa. Está constituida por lutitas, calizas arcillosas y calizas finamente laminadas; su color gris a pardo amarillento pasando por el rosado, se debe al intemperismo. La edad de esta formación ha sido determinada como del Aptiano Inferior, del Barremiano o ambos (Robeck et al., 1956).

Caliza Cupido. Aflora en el Potrero de Ovallos, Cañón de la Alameda y en la Sierra de Santa Rosa. Consiste de calizas de color gris oscuro a negro, con estratificación delgada cerca de la base, pero con estratos de 3 a $4 \mathrm{~m}$ de espesor cerca de la cima; la parte superior forma escarpes macizos. Su edad está considerada como del Aptiano.

Formación La Peña. Aflora en las Sierras de Santa Rosa, Las Hermanas y en la Sierra Azul. Está compuesta de lutitas carbonosas y estratos delgados de caliza arcillosa, con espesores que oscilan alrededor de $50 \mathrm{~m}$. La formación constituye un talud prominente entre los escarpes de las calizas Cupido y Aurora, que marcan sus límites inferior y superior. Este talud es fácil de identificar y por lo tanto es un índice muy útil en la planificación. De acuerdo con Imlay (1937), la presencia de Dufrenoya texana Burckhardt y de Cheloniceras cf. C. Wilfrid (Burckhardt), indican que la formación es del final del Aptiano.

Caliza Aurora. Constituye las principales serranías y escarpaduras de los estados de Coahuila y Chihuahua. Un afloramiento típico puede observarse en la localidad de El Cedral en Coahuila. Esta caliza está compuesta de estratos gruesos, macizos de caliza gris, con rudistas. En la capas superiores es común la presencia de nódulos de pedernal. Su edad es del Albiano y constituye la formación más persistente y ampliamente distribuida en México y Texas. La sección tipo está localizada al oriente de Chihuahua, en el lugar conocido con el nombre de Cuchillo Parado. La caliza Aurora es equivalente a las calizas Georgetown y Edwards de Texas y a las de Cuesta del Cura, Tamaulipas, el Abra, Tamabra, Tamiahua y Taninul de la parte central y oriental de México.

Caliza Buda. Esta formación aflora al noroeste y está compuesta de caliza con estratificación delgada probablemente se acuña hasta desaparecer antes de cubrir el borde septentrional del área carbonífera, cerca de El Tule. Su edad es Cretácico Superior.

Lutita Eagle Ford. La Formación Eagle Ford descansa en concordancia con la caliza Aurora, en El Cedral en el lado noroeste de la Sierra de Santa Rosa. Consiste en estratos alternados de limolitas calcáreas, de color gris oscuro y calizas con estratificación delgada que han sido llamadas "Lajas de Boquillas". Los fósiles identificados en la formación indican que su edad varía desde el final del Cenomaniano hasta el Turoniano inclusive. El espesor es de cerca de $200 \mathrm{~m}$ en El Cedral pero en otras áreas es por lo menos el doble (Robeck et al., 1956).

Creta Austin. La Creta Austin y la lutita Eagle Ford, tienen casi la misma litología, y por lo general las dos formaciones no se consideran separadamente en el campo. El espesor de la Creta Austin es casi igual al de la lutita Eagle Ford, y parecen aumentar y disminuir para ambas formaciones en las mismas áreas geográficas. En los estratos de la cima, es común encontrar grandes ejemplares de Inoceramus undulatoplicatus Roemer, negros y aplanados, fósiles característicos de la Creta Austin y que sirven como índice para distinguirla fácilmente de la lutita Eagle Ford. Muchos de los fósiles identificados prueban que la edad de la Creta Austin abarca del Coniaciano al Santoniano (Robeck et al., 1956).

Arcilla Upson. La localidad tipo se encuentra cerca de Eagle Pass, Texas en donde la formación consiste de $170 \mathrm{~m}$ de limolitas de inicios del Campaniano. En el área carbonífera de Coahuila la Formación Upson ha sido reconocida en El Cedral, en los piloncillos y en el pozo artesiano de Nueva Rosita.

Formación San Miguel. Su localidad tipo se localiza en Eagle Pass, Texas. En México aflora en varias partes del área planificada de la región de Sabinas. La formación esta constituida por limolitas de estratificación delgada que cambian gradualmente hacia arriba hasta limolitas sin estratificación y a algunas areniscas estratificadas con varias especies de fósiles marinos del final de Campaniano. Su espesor en el área de Sabinas es del orden de $270 \mathrm{~m}$ (Robeck et al., 1956).

Formación Olmos. La Formación Olmos, cuya edad es Cretácico Tardío (Robeck et al., 1956), es conocida también como "Formación del Carbón". Es la de mayor importancia económica ya que contiene los principales mantos de carbón. Fue definida por L.W. Stephenson (1927, p. 14), quien la describió de la manera siguiente :

"La discordancia entre las formaciones Taylor y Navarro se continúa hacia el occidente entre la caliza Anacacho y la formación suprayacente Escondido, pero en Maverick Country, el hiato estratigráfico representado por la discordancia, se encuentra parcialmente cubierto por capas no 
marinas, conocidas hasta ahora como "coal series" y aquí denominadas Formación Olmos, que se interponen entre las Formaciones San Miguel y Escondido.

El nombre Olmos se tomó de la estación ferroviaria de bandera: Olmos, ubicada sobre el afloramiento de la formación, y del Arroyo Olmos, que sigue el rumbo de la formación cerca del centro de la zona del afloramiento desde un punto a 7 u 8 millas al norte de Eagle Pass, hasta la confluencia del arroyo con el Río Grande. El espesor de la formación varía desde casi imperceptible hasta 400 ó 500 pies. La formación consiste de arcilla lutítica gris verdosa y arcilla arenosa fina, interestratificadas irregularmente con arenisca gris verdosa, fina a gruesa, blanda a dura, de estratificación delgada a maciza, más o menos diastratificada, que contiene algunas capas con ondulitas y mantos de carbón y lignito. Parece haber discordancia tanto en la base cono en la cima de la Formación Olmos".

Robeck et al. (1956) mencionan que en el área de Sabinas no es posible planificar individualmente los estratos de la Formación Olmos, debido a su excesiva naturaleza lenticular. Sin embargo, se determinaron cinco zonas litológicas planificables; estas zonas no se definieron al grado de poder considerarlas como miembros de la Formación Olmos.

En la sección de El Cedral, la zona del carbón tiene $36 \mathrm{~m}$ de espesor; consiste de un doble manto de carbón y localmente, dos o tres mantos lenticulares, delgados, arriba del doble manto. El resto de la zona está compuesto por argilitas en la base, que varía hacia arriba a limo y finalmente cambia a arena fina, en un horizonte por lo regular indefinido.

Formación Escondido. La edad de esta formación es Cretácico Tardío y se encuentra cubriendo concordantemente a la Formación Olmos. Su localidad tipo esta en la confluencia del Río Escondido, cerca de Piedras Negras y más o menos sigue el curso del Río Bravo aguas abajo, por 60 kilómetros, hasta Loma Prieta donde esta expuesto el contacto entre el Cretácico y las capas del Eoceno (Dumble, 1892). Robeck et al. (1956), señalan que en el área de Sabinas esta formación está expuesta a lo largo del camino de Nueva Rosita a la de Las Esperanzas, pero en general son escasos los afloramientos. Está compuesta por limolita y argilitas macizas a físiles, contiene algunas lentes calcáreas fosilíferas que aumentan en número, espesor y longitud hacia arriba de la sección, hasta formar estratos de $0.05 \mathrm{~m}$ de espesor. Estos estratos son totalmente diferentes de los de la Formación Olmos y es por esto que la unidad esta colocada en la Formación Escondido.

Formación Múzquiz. Los estudios detallados realizados por Robeck et al. (1956) en El Cedral demostraron la presencia de capas de color rojo claro suprayaciendo a la Formación Escondido. Esta formación consiste de capas rojas continentales, de colores claros, que varían de argilitas macizas en tonos verde, castaño, rojo y gris, a limolitas y areniscas estratificadas de color rojo. En la sección del Cedral todas las capas de la Formación Escondido son grises, pero adquieren diversas tonalidades de pardo por intemperismo, en contraste con el color rojo claro de la Formación Múzquiz. En esta sección Stephenson (in op. cit.) identificó Ostrea n. sp., considerándolas semejantes a algunas formas del Terciario. Sin embargo, se han encontrado restos de amonitas identificadas como Coaahuilites Cheltoni Bose, de edad Maastrichtiano, en capas intercaladas con la zona de color pardo claro. Por consiguiente la Formación Múzquiz representa la parte final del período Cretácico y el fin de la sedimentación marina dentro del área planificada (Robeck et al., 1956).

Conglomerado Sabinas. Durante el Terciario toda la región quedó sobre el nivel del mar, sujeta a la erosión. Ya durante el Plioceno se depósito sobre aproximadamente la tercera parte del área una capa muy extensa de grava, a la que se ha llamado conglomerado Reynosa. Robeck et al. (1956) proponen el nombre de Conglomerado Sabinas para su uso en México, debido a que el conglomerado presenta múltiples afloramientos en la ciudad de Sabinas y a lo largo del río del mismo nombre. La formación esta restringida a las terrazas de grava más altas que normalmente se levantan de 20 a $30 \mathrm{~m}$ sobre los valles adyacentes.

El Conglomerado Sabinas consiste de gravas de calizas más o menos cementadas por carbonato de calcio. El tamaño de los constituyentes de la grava varia desde bloques angulosos de un metro, cerca de las montañas, hasta guijarros de $5 \mathrm{~cm}$ de diámetro o menores en Don Martín, a $70 \mathrm{~km}$ de las montañas. Localmente, como en los piloncillos, la formación consiste de 5 a $6 \mathrm{~m}$ de caliza maciza en la que no hay guijarros. En el Cedral, el espesor de la formación es de unos $15 \mathrm{~m}$ en el afloramiento que hay bajo la corriente de lava que cubre esa región.

Lava Esperanzas. Durante el Cuaternario hubo cuando menos siete fisuras por donde se derramaron corrientes de lava, que fluyeron por distancias considerables, siguiendo acaso canales existentes en el Conglomerado Sabinas, que formaba una superficie casi horizontal. El nombre de lava Esperanzas fue propuesto por Mullerried en 1941, debido a su proximidad a la población de Las Esperanzas.

Las corrientes de lava están cubiertas por una capa muy delgada de suelo y por lo regular parecen haber sido poco afectadas por la erosión; su extensión ha sido un poco reducida en sus flancos por la erosión en tiempos muy recientes. La delgada cubierta de suelo indica que las corrientes de lava tienen cuando menos 15,000 años, pero su posición estratigráfica y la falta de erosión indica que su edad queda definitivamente dentro del Pleistoceno.

Terraza de grava y limo. De acuerdo con Robeck et al., (1956) durante el Cuaternario hubo varios lugares donde se depositaron cantidades variables de grava y limo, quedando sujetos a la erosión. Probablemente hubo varios factores que causaron la obstrucción de los cauces de algunos arroyos formando barriales y lagos transitorios durante el final del Plioceno y Pleistoceno. Entre esos factores tal vez figuraron movimientos tectónicos, cambios climáticos y bloqueo de los cauces por corrientes de lava. Todos estos 
depósitos, cuya edad comprende desde el final del Terciario al Reciente, han cubierto las rocas cretácicas como en la mitad del área. Actualmente las corrientes fluviales ya no están bloqueadas $\mathrm{y}$, con excepción de los lugares cercanos a las montañas, están causando degradación de sus cauces. Cerca de las montañas se están rellenando con grava (Robeck et al., 1956).

Estructuralmente, las rocas sedimentarias de la región adoptan la forma de anticlinales y sinclinales de dimensiones relativamente grandes, estructuras que presentan complicaciones locales tales como recostamientos, plegamientos subordinados en las calizas de estratificación delgada, y adelgazamiento de las formaciones lutíticas; estas rocas están también afectadas por diapiros de yeso y cuerpos ígneos intrusivos. Las rocas plegadas más jóvenes son del final del Cretácico y sobre ellas descansa en posición discordante el conglomerado Sabinas, considerado como del Plioceno.

De todas las estructuras la más larga es el anticlinal de la Sierra de Santa Rosa, el cual tiene 120 kilómetros de longitud; la más corta es el anticlinal de Metatosa, que tiene tan sólo $10 \mathrm{~km}$. El anticlinal de la Sierra de la Gloria se levanta hasta unos 2,200 metros sobre el nivel del mar y 1,540 metros sobre el nivel de los valles adyacentes, y es el que exhibe el mayor relieve estructural en la región; el de menor relieve es el anticlinal de Metatosa, con 700 m (Robeck et al., 1956).

Todos los anticlinales buzan en sus extremos hacia las cuencas adyacentes. Por lo regular la cresta de los anticlinales mantiene la misma elevación por varios kilómetros, tal como se observa en la Sierra de Santa Rosa, pero en sus extremos buzan bruscamente hacia las cuencas. En otros, como en la Sierra de la Laja, la cresta presenta una curvatura contínua entre uno y otro extremo (Robeck et al., 1956).

Los anticlinales son por lo regular más empinados en su flanco noreste, donde es común encontrar inclinaciones de $70^{\circ}$, aunque también hay lugares donde las capas son verticales o ligeramente recostadas. En los flancos suroeste, de la mayoría de este tipo de estructura la inclinación varía desde $20^{\circ}$ hasta $60^{\circ}$ (Robeck et al., 1956).

Los sinclinales son cuencas estructurales que se reflejan fisiográficamente en forma de cuencas topográficas. La cuencas que existen al noreste de la Sierra de Las Hermanas son por lo regular poco profundas y de forma elíptica, en tanto que las que se encuentran hacia el suroeste son profundas, alargadas y angostas.

Historia geológica de la Región Carbonífera de Coahuila. La historia geológica de esta región forma parte de los eventos geológicos ocurridos durante el Jurásico y Cretácico en la Región Carbonífera de Coahuila y en la Paleopenínsula de Coahuila localizadas hacia el este. Por los estudios estratigráficos realizados en el área se sabe que esta última península actuó como la fuente principal de los sedimentos depositados en la Cuenca de Sabinas, principal- mente durante el Jurásico Tardío y el Cretácico Temprano, ya que a partir del Cretácico medio la continua transgresión marina se extendió considerablemente hacia el oeste y cubrió los últimos vestigios de la Península de Coahuila (Robeck. et al., 1956; Salas y Benavides, 1976).

Al terminó del Cretácico Tardío (Campaniano), la región experimentó los primeros efectos, de la deformación Larámide, lo que motivó una regresión general del mar hacia el oriente. Finalmente en el Maastrichtiano, la zona que corresponde en la actualidad a la Región Carbonífera, formaba parte de una extensa planicie deltaica, caracterizada por una vegetación exuberante y la presencia de amplias e irregulares zonas palustres, en las cuales se acumuló y preservó la materia orgánica. Inicialmente este material se transformó en productos carbonosos de bajo grado, como turba y lignito; sin embargo, los eventos tectónicos de la deformación Larámide, motivaron su conversión en carbones de grado más elevado carbón bituminoso y carbón sub-bituminoso, que se explotan hoy en día en la mencionada Región Carbonífera de Coahuila (Salas y Benavides, 1976).

Recursos en la Región Carbonifera de Coahuila. Dentro de estas subcuencas, la de Sabinas es la mejor conocida debido a su intensa explotación de carbón, tiene 62 kilómetros de longitud, con una anchura máxima de 24 kilómetros. La profundidad máxima a la que se encuentra el manto de carbón es de $490 \mathrm{~m}$, en un lugar que está como a 6 kilómetros al oriente de Los Piloncillos. La subcuenca de Esperanzas, localizada al poniente de la subcuenca de Sabinas, también ha sido objeto de exploración y explotación; tiene $34 \mathrm{~km}$ de longitud, con una anchura máxima de $7 \mathrm{~km}$. (Robeck et al., 1956).

El carbón explotable se encuentra principalmente en las "subcuencas" de Sabinas y de Esperanzas. Se presenta como un doble manto separado por un cuerpo arcillo-limolítico. En los demás depósitos conocidos de las otras subcuencas, no siempre se encuentra el segundo manto. En la cima del segundo manto, aparece un horizonte de arcilla refractaria de 25 a $30 \mathrm{~cm}$ de espesor, que corresponde probablemente a una toba volcánica transformada parcialmente en bentonita. Este horizonte es un índice confiable para la correlación de los mantos de carbón de una mina a otra, así como para la correlación de áreas próximas entre sí (Figuras 6 y 7).

El carbón de estas subcuencas (Tabla 1) es de tipo sub-bituminoso apropiado para su transformación en coque, tiene volatilidad media a baja, presenta vitrinita preponderante como constituyente, y un poder reflector de la vitrinita de 0.6-1.2 \% (Piedad-Sánchez et al., 2005). En cuanto a las reservas, al año de 1993 se estimó un potencial total de 1,387'22,586 Ton. (Rivera-Martínez y Alcocer-Valdés, 2003).

En la sub-región "Zona de Fuentes-Río Escondido", la litología de las unidades estratigráficas del Cretácico Tardío que contienen los horizontes de carbón, es prácticamente 


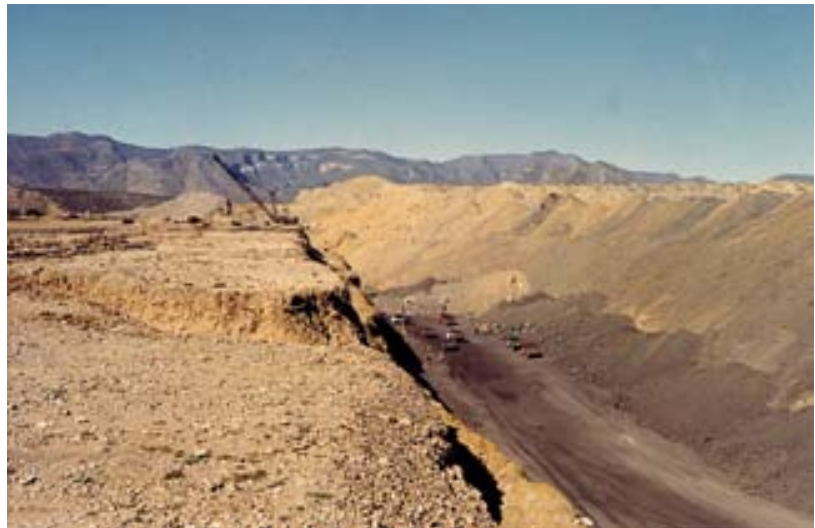

Figura 6. Vista panorámica del tajo La Florida ubicado en la subcuenca Saltillito-Lampacitos. Abajo en color negro se observa el manto principal de carbón de edad cretácica, el cual tiene en promedio 1.6 a $1.8 \mathrm{~m}$ de espesor (Fotografía del 11 de enero de 1972 tomada por el Ing. Luís Benavides).

la misma que los depósitos contemporáneos de la cuenca de Sabinas. La diferencia está en el tipo de carbón que posee, ya que se trata de carbón sub-bituminoso "C", de alta volatilidad (de flama larga), poco apropiado para que se le pueda transformar en coque (Tabla 1).

De acuerdo con las normas A.S.T.M. el carbón de la zona Fuentes-Río Escondido corresponde a un tipo de alta volatilidad bituminoso "C", y con base en la clasificación de combustibles fósiles sólidos, este carbón queda clasificado como tipo vítrico con más de $65 \%$ de vitrinita y de facies mixta cuya materia mineral excede el $20 \%$ (Verdugo y Ariciaga, 1988a, b).

Desde el punto de vista estructural, los sedimentos carboníferos de esta zona forman un monoclinal contínuo, buzando hacia el noreste, por lo cual dichas unidades quedan pronto cubiertas por las formaciones marinas del Terciario que afloran hacia el este y que constituyen la Planicie Costera del Golfo de México (Figuras 8 y 9).

De acuerdo con Rivera-Martínez y Alcocer-Valdés, (2003) los mantos de carbón detectados se encuentran desde la superficie hasta los $250 \mathrm{~m}$ de profundidad, tienen espesores de 0.10 hasta $2.50 \mathrm{~m}$, presentándose por lo general de dos a seis mantos, con separaciones de 0.50 a $20 \mathrm{~m}$.

El depósito está asociado a un sistema deltaico que se desarrolló durante el Maastrichtiano-Campaniano y que ha sido clasificado como del tipo constructivo lobulado. Sus facies están representadas por las formaciones Upson (prodelta), San Miguel (frente deltaico) y Olmos (planicie deltaica), siendo esta última la que contiene, hacia su base, los mantos de carbón con espesores económicos (Verdugo y Ariciaga, 1988b).

Los trabajos de exploración, realizados en forma coordinada por la Comisión Federal de Electricidad y por Minera Carbonífera Río Escondido, S.A. (Micare, 1982) permitieron comprobar reservas del orden de 600 millones de toneladas de carbón sub-bituminoso, de flama larga, cuyas características se pueden consultar en la Tabla 1.

De acuerdo con el programa de diversificación energética, la Comisión Federal de Electricidad desarrolló en el año 1982 un proyecto termo-eléctrico, para generar 1,200 MW que consumirían 4.3 millones de toneladas de carbón por año, extraído de la cuenca carbonífera Fuentes-Río Escondido.

Es importante señalar la alternativa del aprovechamiento del gas grisú asociado al carbón mineral de las cuencas carboníferas de Coahuila, debido tanto a las características bituminosas del carbón como a las condiciones estructurales de sus capas. La mina Pasta de Conchos, en el mismo Estado, inició un programa de desgasificación a principios de los 90's, debido a que la mina detectó valores $>1 \%$ en el aire de retorno de la ventilación; para lo cual utilizó barrenación horizontal de los mantos previo al minado. El proyecto logró bajar las concentraciones de gas en el aire de $1.5 \%$ a $0.4 \%$ (Querol, 2005).

Minerales Monclova reporta un contenido de gas grisú en la subcuenca de Sabinas de 10 a $14 \mathrm{~m}^{3} / \mathrm{t}$, y de 12 a 18 $\mathrm{m}^{3} / \mathrm{t}$ en los carbones de la subcuenca Saltillito. Como sería

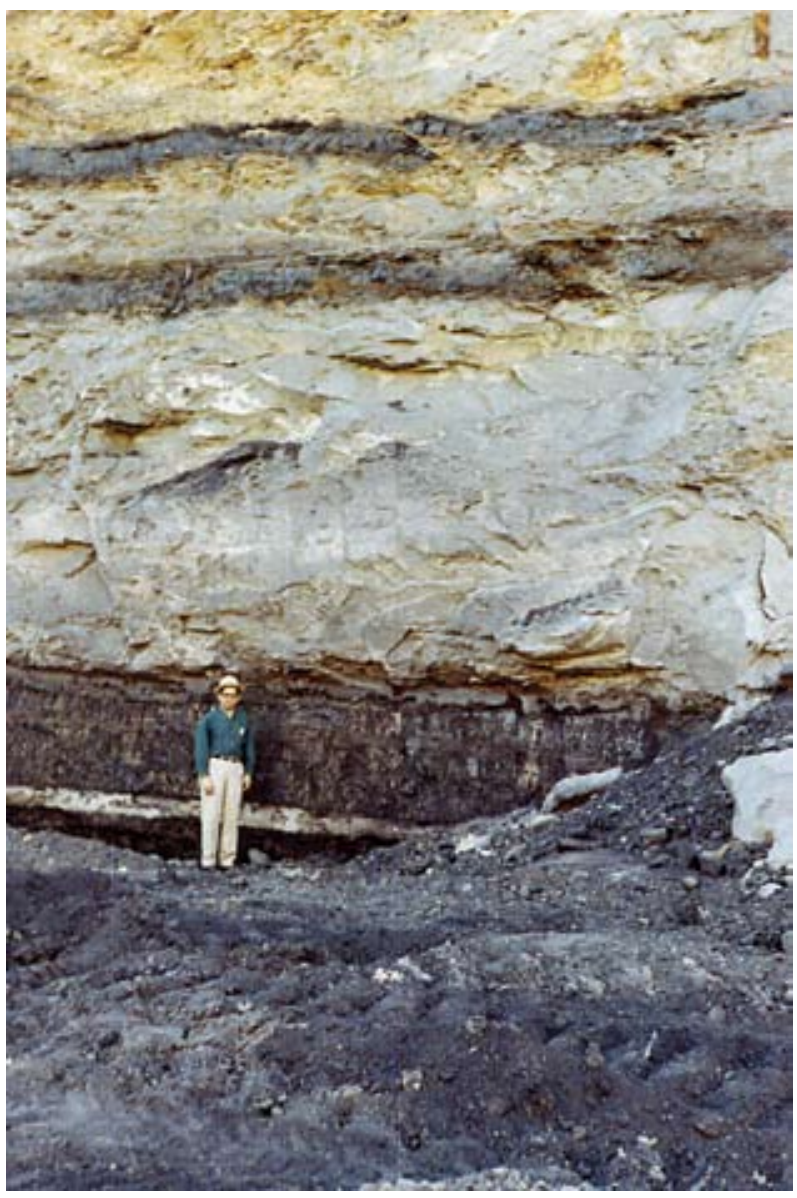

Figura 7. Detalle del tajo La Florida que muestra la parte superior del manto principal de carbón (color oscuro). Arriba, en la foto, se observan dos capas delgadas de carbón con impurezas (Fotografía del 11 de enero de 1972 tomada por el Ing. Luís Benavides). 
Tabla 1. Estimación de reservas y características del carbón de las principales cuencas de México.

\begin{tabular}{|c|c|c|c|c|c|c|c|}
\hline & $\begin{array}{c}\text { Sabinas-Monclova, } \\
\text { Coah. } \\
\text { Rivera y Alcocer } \\
\text { (2003) }\end{array}$ & $\begin{array}{c}\text { Fuentes-Río } \\
\text { Escondido, Coah. } \\
\text { Verdugo y Ariciaga } \\
(1988 b)\end{array}$ & $\begin{array}{l}\text { Colombia-San Ignacio, } \\
\text { Coah, N.1., Tam. } \\
\text { Rivera y Alcocer } \\
(2003)\end{array}$ & $\begin{array}{c}\text { Tezoatlán } \\
\text { - Mixtepec, Oax. } \\
\text { Ojeda-Rivera (1975) } \\
\text { y Flores-Galicia } \\
(1988)\end{array}$ & $\begin{array}{c}\text { San Marcial-Sta } \\
\text { Clara, Son. } \\
\text { Flores-Galicia } \\
\quad(1988)\end{array}$ & $\begin{array}{c}\text { Cabullona, Son. } \\
\text { Flores-Galicia, } \\
1988\end{array}$ & $\begin{array}{c}\text { San Pedro } \\
\text { Corralitos, Chih. } \\
\text { Flores-Galicia } \\
1988\end{array}$ \\
\hline $\begin{array}{l}\text { Reservas } \\
\text { (Toneladas) }\end{array}$ & $538 ’ 234,684^{*}$ & $419^{\prime} 000,000^{*}$ & $56^{\prime} 966,618^{*}$ & $32^{\prime} 500,000^{*}$ & $4^{\prime} 755,000 *$ & $80^{\prime} 000,000$ & $5^{\prime} 800,000$ \\
\hline $\begin{array}{l}\text { Carbón fijo } \\
(\%)\end{array}$ & 45.61 & 36 & $21.9-32.4$ & 50.13 & $95.3 \ominus$ & 67.45 & 21.3 a 36.23 \\
\hline $\begin{array}{l}\text { Materia } \\
\text { volátil (\%) }\end{array}$ & 16.97 & 27 & $34.4-42.6$ & 37.37 & - & 9.92 & 22.8 a 33.6 \\
\hline Ceniza (\%) & 40.43 & - & $21.5-44.0$ & 22.50 & - & 18.86 & 39.9 a 55.9 \\
\hline Azufre (\%) & 01 & 01 & $1.2-3.5$ & 0.47 & 0.37 & 0.0 & 0.23 a 0.49 \\
\hline $\begin{array}{l}\text { Poder } \\
\text { calorífico }\end{array}$ & - & $4,400 \mathrm{cal} / \mathrm{kg}$ & $4,481-6189 \mathrm{cal} / \mathrm{kg}$ & $12,468 \mathrm{BTU} / \mathrm{lb}$ & $6,300 \mathrm{cal} / \mathrm{kg}$ & $5,034 \mathrm{cal} / \mathrm{kg}$ & - \\
\hline $\begin{array}{l}\text { Gas metano } \\
(\mathrm{m} / \mathrm{tn})\end{array}$ & - & 5 & - & 5 & - & - & - \\
\hline $\begin{array}{l}\text { Hidrógeno } \\
(\%)\end{array}$ & - & - & - & - & 1.6 & - & - \\
\hline $\begin{array}{l}\text { Nitrógeno } \\
(\%)\end{array}$ & - & - & - & - & 0.36 & - & - \\
\hline $\begin{array}{l}\text { Oxígeno } \\
(\%)\end{array}$ & - & - & - & - & 7.8 & - & - \\
\hline $\begin{array}{l}\text { Temp. de } \\
\text { fusión de } \\
\text { ceniza }\left({ }^{\circ} \mathrm{C}\right)\end{array}$ & - & - & - & - & 1280 & 1280 & - \\
\hline
\end{tabular}

*Probadas; $\ominus$ Carbón fijo a base seca y libre de materia mineral

de esperar, el contenido de gas varía con la profundidad, por lo que a $180 \mathrm{~m}$ dicho contenido disminuye hasta 8 $\mathrm{m}^{3} / \mathrm{t}$ en la subcuenca de Sabinas. Este gas presenta una composición, en promedio, de más del $97 \%$ de metano, con cantidades menores y variables de etano, propano y dióxido de carbono (Querol, 2005).

Actualmente MIMOSA genera de sus minas subterráneas en promedio $65 \cdot 10^{3} \mathrm{~m}^{3}$ de gas por año, de los cuales el $86 \%$ es drenado a través de la ventilación a la atmósfera, el $6 \%$ a través de los barrenos horizontales, y el $8 \%$ a través de barrenos verticales en los caídos.

El cálculo basado en los recursos totales de los carbones Maastrichtianos de Coahuila y en su contenido en gas, con respecto a las subcuenca de Sabinas y Saltillito, indican recursos de gas metano total entre $1.22 \times 10^{11}$ y $2 \cdot 2 \times 10^{11}$ $\mathrm{m}^{3}$ respectivamente (Querol, 2005).

\subsubsection{Región carbonífera de Colombia-San Ignacio, Estados de Tamaulipas, Coahuila y Nuevo León}

Esta región ha sido poco explorada. Sin embargo se incluye aquí por su ubicación en el NE de México. Forma parte de la Cuenca de Burgos, ubicada en el Estado de Tamaulipas y una porción de los de Nuevo León y Coahuila, ocupando el norte de la Planicie Costera del Golfo de México (Figura 3).

En esta cuenca afloran formaciones marinas terciarias, dispuestas en franjas orientadas NW-SE, cuya edad disminuye hacia el oriente. Estas formaciones registran la regresión generalizada del mar, asociada a levantamiento regional; sin embargo el proceso regresivo dominante, estuvo afectado por numerosas oscilaciones transgresivo/regresivas que produjeron avances y retrocesos del litoral, expresados en las interdigitaciones de los depósitos sedimentarios.

La columna estratigráfica esta representada en su totalidad por rocas sedimentarias de edad Eoceno y materiales aluviales recientes. En su mayoría corresponden a lutitas, areniscas, limolitas y conglomerados, que constituyen las formaciones Midway, Wilcox, Carrizo, Bigford, Pico Clay, Laredo, Uvalde y las arenas, gravas y conglomerados mal consolidados, que conforman los depósitos del Reciente (Rivera-Martínez y Alcocer-Valdés, 2003).

Las unidades de mayor interés las representan las formaciones Bigford y Pico Clay del Terciario, ya que en la cima de la primera y en la base de la segunda se localizan los mantos de carbón que representan el interés económico de esta cuenca.

Los programas de exploración realizados en diferentes épocas tanto por Comisión Federal de Electricidad como por el Consejo de Recursos Minerales, han permitido detectar la presencia en esta cuenca hasta nueve mantos de carbón, con espesores que van desde $0.17 \mathrm{~m}$ hasta $0.60 \mathrm{~m}$ y profundidades que van desde la superficie del terreno hasta los $150 \mathrm{~m}$. En general los mantos presentan una actitud subhorizontal, con inclinaciones de $2^{\circ}$ a $4^{\circ}$ hacia el NE.

El carbón de esta cuenca fue clasificado de como lignito brillante sapropélico a lignito brillante vítrico (Tabla 1; Rivera-Martínez y Alcocer-Valdés, 2003). Las reservas de carbón han sido cuantificadas en el área de Villa Hidalgo 


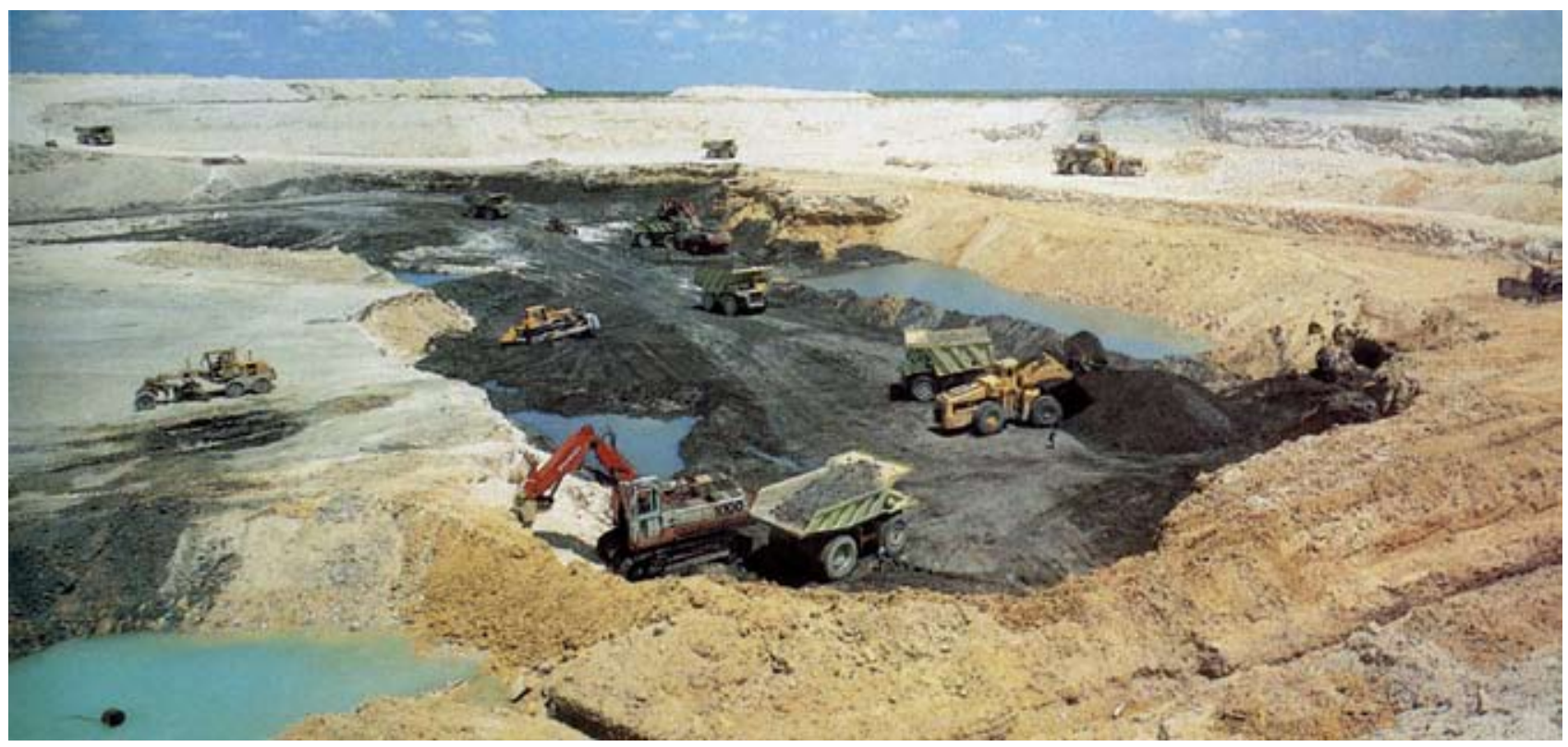

Figura 8. Vista panorámica del tajo de carbón en Piedras Negras, Coah. Incluido en la sub-región de Fuentes-Río Escondido. Abajo el color negro corresponde a la cima de la capa principal, la cual esta dentro de la Formación Olmos del Cretácico.(Foto de Micare, 1982).

en 5'914,169 toneladas medidas, 5'152,249 indicadas y 2'232,800 inferidas y en la zona de Colombia-San Ignacio $51^{\prime} 052,449$ toneladas probadas y susceptibles de explotación (Rivera-Martínez y Alcocer-Valdés, 2003).

\subsubsection{Región carbonifera de Tezoatlán-Mixtepec, Oaxaca}

Se localiza en la porción noroccidental del Estado de Oaxaca y se extiende hacia los vecinos estados de Puebla y de Guerrero, quedando incluida dentro de la provincia fisiográfica de la Sierra Madre del Sur (Raisz, 1959). La zona mejor estudiada corresponde a la región de Mixtepec-El Consuelo-Tezoatlán, Oaxaca (Figura 3).

Los mantos de carbón se encuentran en la parte inferior de las Formaciones Rosario, Zorillo y Simón del Jurásico Medio (Erben, 1956a, b), constituidas por una alternancia de areniscas, lutitas y limolitas, depositadas probablemente en un ambiente deltaico. El espesor de las capas de carbón varía de unos cuantos centímetros hasta $3 \mathrm{~m}$, con configuraciones muy variadas (Figura 10). En distancias cortas, se adelgazan o se engruesan, se subdividen o vuelven a juntarse, desaparecen casi por completo o se dispersan súbitamente (Ojeda-Rivera, 1975). Sin embargo, en algunas áreas se han detectado mantos de cientos de metros de longitud, aunque persiste la lenticularidad, la variabilidad de espesor y su interestratificación con roca intermedia (Ojeda-Rivera, 1975). De esta secuencia se ha descrito la flora jurásica mejor conocida de México (Wieland, 1914; Silva-Pineda, 1969, 1978, 1984; Corona-Esquivel et al., 1995).

Debido a las condiciones sedimentológicas inherentes a su formación y a procesos orogénicos posteriores, buena parte de los mantos de carbón presentan altos contenidos en impurezas. Además, están afectados por una fuerte tectónica deformativa que, aunado a la influencia de numerosas intrusiones ígneas, ha dado lugar a que los depósitos de carbón, junto con las unidades sedimentarias que los contienen, se encuentren en forma de bloques aislados por numerosas fallas, lo cual limita la continuidad de las capas de carbón y sus posibilidades de explotación económica. (Cortés-Obregón et al., 1957; Salas y Benavides, 1976).

Uno de los pocos bloques que parece tener cierta homogeneidad se localiza en las cercanías de El Consuelo. Según estudios del extinto Consejo de Recursos Minerales, teniendo en cuenta la multitud de factores positivos y negativos, sobre todo estos últimos, que intervienen en la distribución de carbón del área de Tezoatlán, se estima que esa área contiene un tonelaje máximo probable de 30 millones de toneladas de carbón y un tonelaje posible de 30 millones más (Ojeda-Rivera, 1975).

De estas reservas solamente los 30 millones de toneladas, probables y posibles del Cerro de San Juan Viejo tienen posibilidades de aprovechamiento económico, bajo las condiciones actuales de explotación, no solo por la cantidad y calidad del carbón, sino por su distribución.

Los 30 millones de toneladas restantes corresponden a las reservas probables y posibles de las áreas de El Consuelo y Sayuyá-Santa Catarina. Estas reservas no tienen ninguna posibilidad de aprovechamiento económico inmediato, pero si constituyen una reserva confiable que puede llegar a ser económica por sí sola, si continúa subiendo de precio el carbón, o que podría utilizarse como reserva emergente de un proyecto termo-eléctrico en el que se tratase de aprovechar las reservas del Cerro de San Juan Viejo (OjedaRivera, 1975). 


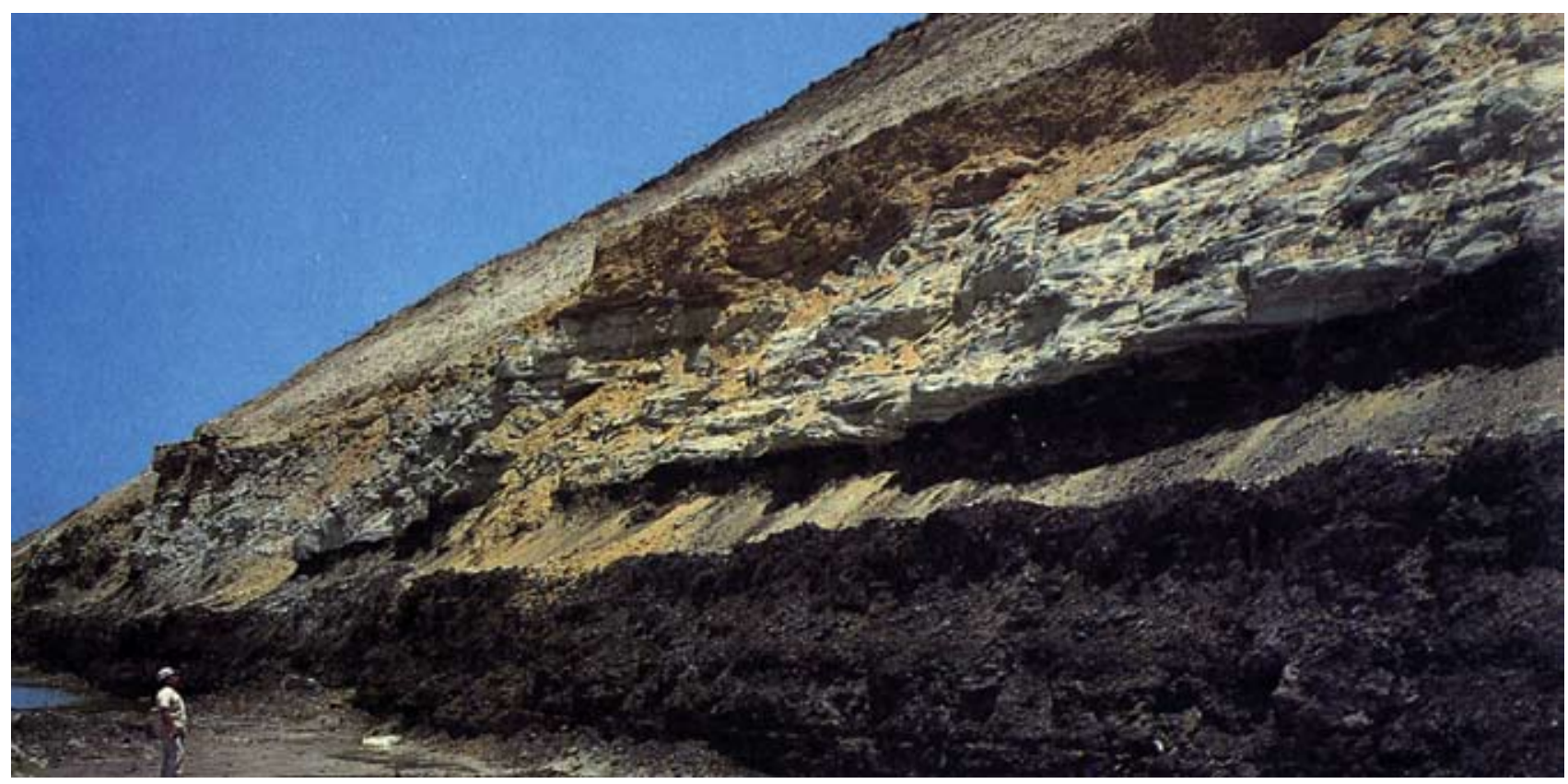

Figura 9. Detalle del tajo de carbón en Piedras Negras, Coah. Se observa el manto principal con una capa de limonita intercalada. (Foto de Micare, 1982).

Asimismo, en la Monografía Geológico-Minera del Estado de Oaxaca (1996) se indica para el área de Tezoatlán -El Consuelo reservas probables 18.6 millones de toneladas, con $37.18 \%$ de carbón fijo y $38.14 \%$ de cenizas.

Cabe destacar, que está región está mal comunicada, y que carece de la infraestructura para la explotación del carbón a corto plazo. Sin embargo, dado que el país está bien interconectado con líneas de alto voltaje, y que se requiere generar electricidad, el carbón de la región podría utilizarse para este fin (Salas y Benavides, 1976).

\subsubsection{Región carbonifera de San Marcial-Santa Clara, Sonora}

Se localiza en la parte central del Estado de Sonora, aproximadamente a $90 \mathrm{~km}$ al sur de Hermosillo, en la Provincia Fisiográfica Desierto de Sonora (Raisz, 1959). La geología y los depósitos de carbón han sido investigados por Dumble (1899), Flores (1930), King (1939), Wilson y Rocha (1946), y Flores-Galicia (1988). Según el Consejo de Recursos Minerales (1994), se han encontrado también evidencias carboníferas en las regiones de Santa Clara, San Enrique, Sierra Verde, Los Vasitos y El Cocinero, pero la de San Marcial, sigue siendo la más importante. En Sonora se encuentran evidencias de grafito en las regiones de San José de Moradillas (El Cochi), Onavas y La Igualama.

La unidad portadora tanto de los mantos de carbón como del grafito es la Formación Barranca (King, 1939) del Triásico, elevada a Grupo por Alencáster (1961). Está constituida por conglomerados, areniscas y limolitas rojas con intercalaciones de lutitas y mantos de carbón y grafito (Rangin, 1978; Roldán-Quintana, 1984). Flores-Galicia (1988) menciona que las unidades de esta región están afectadas por varios periodos de deformación, marcados por las discordancias entre las rocas Cretácicas y las volcánicas de principios del Terciario, e intrusionadas por grandes masas plutónicas. Debido a esto, la potente secuencia de la Formación Barranca aparece como bloques dislocados, separados entre sí por grandes distancias, así como el emplazamiento de cuerpos intrusivos indujo el desarrollo de un sistema de fallas radiales. Los depósitos de carbón se encuentran interestratificados en el miembro inferior, donde los sedimentos son finos y carbonosos. El carbón se encuentra bajo la forma de mantos lenticulares, adelgazándose hasta confundirse con los sedimentos carbonosos, o bien se acuñan entre dos capas de cuarcita o una lutita $\mathrm{y}$ otra de cuarcita.

Flores-Galicia (1988) menciona que, con la exploración directa tanto de obra minera como de sondeos con diamante, fue posible identificar cuatro mantos de carbón comerciales. También se reconocieron otros considerados como de menor importancia debido a su poca extensión y espesor. Este autor señala además que la continuidad de los mantos está cortada por numerosas fallas de diferente magnitud y tipo, que producen escalonamientos característicos. Este hecho debe considerarse en la formulación de los proyectos de desarrollo y explotación de estos mantos.

En el área de San Marcial, el carbón es negro, duro, compacto, brillante, con fractura sub-concoidal o cúbica y gravedad específica alrededor de $1.9 \mathrm{~g} / \mathrm{cm}^{3}$. Se presenta bajo dos tipos: el primero de ellos tiende a quebrarse fácilmente en trozos más cuboidales, y es posible recuperarlo íntegramente en los núcleos de exploración; el segundo tipo se rompe con mayor dificultad y es más untuoso al tacto (Flores-Galicia, 1988). 
El carbón de esta región corresponde al tipo 2 de la "clase" antracítica, en el grupo que varía desde la metaantracita hasta la semi-antracita, incluyendo a la antracita. Los resultados de sus análisis se listan en la Tabla 1.

Regionalmente, estos depósitos de carbón se originaron en un ambiente transicional salobre, desarrollado en una gran cuenca, que se extendía en toda la porción centro-oriental del Estado de Sonora. El carbón generado inicialmente fue bituminoso, el que por metamorfismo de contacto subsecuente, asociado al emplazamiento de intrusiones en la Formación Barranca, se transformó en carbón antracítico o en grafito.

Las reservas de carbón calculadas por el Consejo de Recursos Minerales, considerando sólo las áreas de Santa Clara, San Marcial y San Enrique, son de 4,755 millones de toneladas probadas. Dada la gran extensión de la cuenca, es muy probable que mediante la exploración regional, dichas reservas se incrementen sustancialmente.

\subsubsection{Cuenca de Cabullona, Sonora}

Esta cuenca se localiza en el noreste del Estado de Sonora, dentro de los Municipios de Agua Prieta, Naca y Fronteras; se le divide en las áreas Cabullona y El Encino. En esta cuenca afloran unidades que se extienden del Precámbrico al Reciente, dominando las formadas por rocas sedimentarias. Las unidades de mayor interés por contener yacimientos de carbón son las Formaciones Cintura y Snake Ridge del Grupo Bisbee, y la Formación Cabullona, todas del Cretácico (Flores-Galicia, 1988).

La Formación Cintura sobreyace concordantemente a la Caliza Mural, y subyace de igual manera a la Formación Snake Ridge; es una secuencia de areniscas, limolitas, lutitas, calizas, y lentes de conglomerado. Además contiene mantos de carbón, intercalados con lutitas y/o areniscas y calizas con moluscos de ambiente marino somero, tales como Trigonia sp., Turritella sp., y Ostrea sp. del Cretácico Temprano.

La Formación Snake Ridge subyace concordantemente a la Arenisca Camas, tiene un espesor de aproximadamente $650 \mathrm{~m}$, está constituida por capas medianas de conglomerado arenoso, arenisca conglomerática, arenisca de grano grueso, y lutita. Hacia la base, se encuentran dos estratos de lutita carbonosa, que cambian lateralmente a mantos de carbón. (Flores-Galicia, 1988).

El área de Cabullona se extiende lateralmente $13 \mathrm{~km}$, comprende los Sectores San Marcos, Las Fragüitas, Santa Rosa, La Aguja y San Juan. El Sector San Marcos es el de mayor interés, por haberse localizado en él 38 mantos de carbón, material carbonoso o productos de alteración. El sector El Encino es importante también por la presencia de once mantos de carbón (Flores-Galicia, 1988). Los mantos de carbón de ambos sectores están alojados en la Formación Cintura; dado que ésta tiene plegamiento intenso, pudiera haber repetición de mantos.

El carbón de Cabullona corresponde al tipo bituminoso, posteriormente transformado por metamorfismo en antraci- ta y aún en grafito (Tabla 1; Flores-Galicia, 1988).

Debido al bajo grado de exploración en que se encuentra la cuenca de Cabullona, es difícil presentar una evaluación de reservas, ya que se conoce la existencia de los mantos de carbón sólo en afloramientos, desconociéndose su continuidad a profundidad. En base a los estudios geológicos efectuados sólo se puede estimar los posibles recursos existentes en 68 millones de toneladas de carbón para el área de San Marcos y 12 millones para el área de El Encino (Flores-Galicia 1988).

\subsubsection{Cuenca San Pedro Corralitos, Chihuahua}

Esta cuenca se localiza cerca de la estación del ferrocarril San Pedro Corralitos en el Rancho Peña Blanca, situado $50 \mathrm{~km}$ al noreste de Nuevo Casas Grandes, Chih.

El área de San Pedro Corralitos corresponde a un bloque sedimentario de edad Cretácico, preservado de la erosión, que se ubica entre el complejo ígneo intrusivo de la Sierra del Capulín y los grandes intrusivos situados en el extremo nororiental de la Sierra La Escondida.

Este bloque tiene una longitud de $10 \mathrm{~km}$, estructuralmente corresponde a un sinclinal recumbente, cuyo eje mayor se orienta de E-SE a N-NW, su flanco norte es casi vertical, mientras que su flanco sur es más suave, con inclinaciones de $16^{\circ}$ a $40^{\circ}$ al NE. El bloque está delimitado hacia el sureste por el complejo ígneo de la Sierra La Escondida, y hacia el noroeste queda limitado por una falla, que lo pone en contacto con el aluvión cuaternario (Flores-Galicia, 1988).

En la secuencia sedimentaria del Cretácico Tardío se encuentran dos intervalos con varios niveles de carbón,

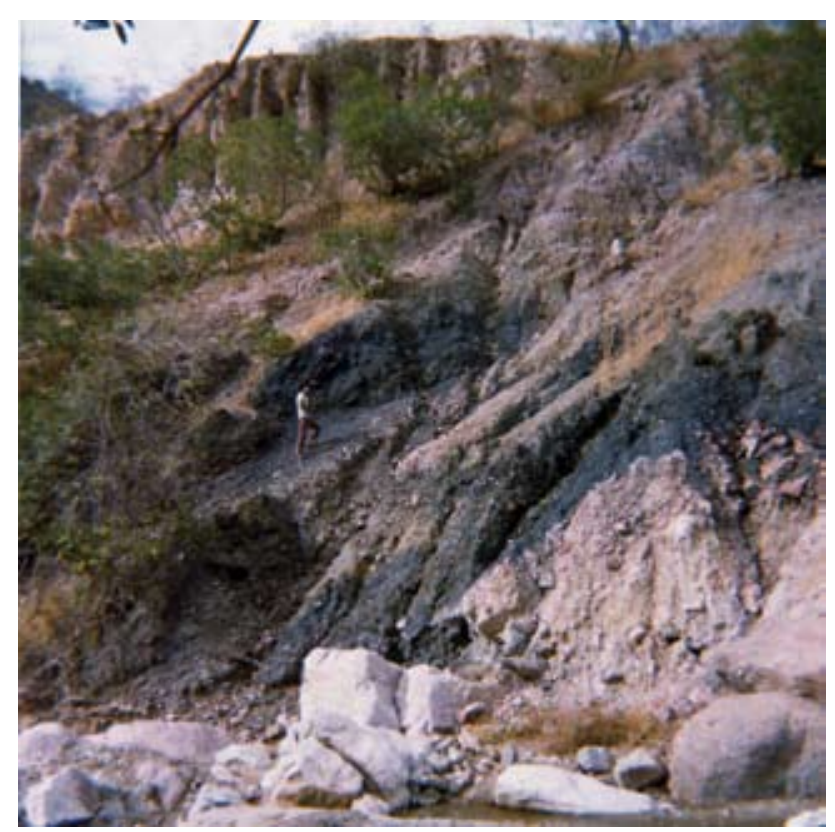

Figura 10. Afloramiento de capas lenticulares carbonosas en rocas jurásicas expuestas en la cañada de Mitlancingo, Guerrero. (Foto de R. Corona, 1977). 
designándoseles de la base a la cima Manto Uno y Manto Dos. El Manto Uno tiene un espesor de $76 \mathrm{~cm}$, y muestra una intercalación lutítica de 4 a $30 \mathrm{~cm}$ de potencia. El carbón es de tipo vitrinítico, y por lo tanto, su contenido de volátiles es alto, como ocurre con el carbón de Coahuila. Hacia la cima, se presentan otros dos horizontes con carbón. El Manto Dos, según Flores-Galicia (1988), tiene un espesor medido de $30 \mathrm{~cm}$, con un nivel carbonoso más pequeño hacia la cima, de unos $10 \mathrm{~cm}$ de espesor. Las reservas de carbón en esta área son de 5.8 millones de toneladas clasificadas dentro de la categoría de inferidas, con un espesor máximo del manto de carbón de $0.70 \mathrm{~m}$.

\subsubsection{Cuenca Ojinaga, Chihuahua}

El carbón de esta cuenca aparece en la Formación Aguja del Maastrichtiano, cuya sección estratigráfica más completa corresponde a la zona del Rancho San José, y comprende dos "unidades" cartografiables, cuyo espesor conjunto es de aproximadamente $400 \mathrm{~m}$.

La unidad marina de $60 \mathrm{~m}$ de espesor, está constituida en la base por una alternancia de capas de lutita gris-oscuro y de arenisca diastratificada, con nódulos calcáreos y abundantes conchas de Exogyra sp. Hacia la parte superior, esta 'unidad' pasa a una secuencia gradacional, formada por capas de arenisca diastratificada de grano fino a grueso, y abundantes moluscos (principalmente gasterópodos, pelecípodos - incluida Ostraea sp.-). Esta unidad se encuentra intrusionada por numerosos dique-estratos.

La unidad continental, tiene en la base un manto de carbón sucio de 0.35 a $0.50 \mathrm{~m}$ de espesor, y un estrato arcilloso con concreciones calcáreo-ferrosas. Hacia la cima está una secuencia limo-arenosa que contiene también abundantes concreciones calcáreo-ferrosas, huesos de dinosaurio, diques y dique-estratos. Coronando la sección se encuentra una cubierta de roca ígnea de composición básica de $8 \mathrm{~m}$ de espesor (Flores-Galicia, 1988).

Las reservas de carbón estimadas en el área son de los 23 millones de toneladas (Flores-Galicia, 1988), sin embargo, los trabajos geológicos efectuados, indican que actualmente, no son susceptibles de explotación económica.

\subsubsection{Otras posibles cuencas carboniferas}

Desde los albores de la minería del carbón en México, la atención industrial se enfocó en las cuencas de Coahuila, concediéndose poca importancia a la exploración sistemática evaluativa de los numerosos depósitos carboníferos existentes en el país. Es así que se han reportado ya algunas localidades de carbón, lignito o turba, pero sólo en pocas se ha estudiado bien la geología, y en ninguna se han cuantificado y evaluado sus reservas

Con base en estudios someros o visitas de reconocimiento, se sabe que existen manifestaciones carboníferas fuera de las cuencas más conocidas y explotadas a nivel comercial en los Estados de Coahuila, Chihuahua, Durango, Guerrero, Hidalgo, México, Michoacán, Oaxaca, Nuevo León, Puebla, San Luis Potosí, Tamaulipas, y Veracruz,
(Salas y Benavides, 1976). La génesis de los depósitos es similar a la ya descrita, y se encuentran principalmente encajonados en unidades litoestratigráficas paleozoicas, jurásicas, cretácicas, eocénicas o más jóvenes. A continuación se les reseña brevemente comenzando por las más antiguas.

La Formación Matzitzi de Puebla (Calderón-García, 1956), con su rica y abundante flora, apenas preliminarmente conocida, y la Formación Los Arcos (Olinalá sic.) de Guerrero (Corona-Esquivel, 1981), son las unidades paleozoicas que podrían contener depósitos de carbón, ya que en ambas unidades se han encontrado estratos de lutitas carbonosas (Corona-Esquivel y Ferrusquía-Villafranca, datos inéditos).

En la Formación Tecomasúchil del Jurásico, que aflora en Tecomatlán, Puebla, y probablemente en otras partes del Estado, como las áreas de Tejaluca y de Ahuatlán, los autores del presente estudio observaron una capa de carbón de buena calidad, en posición sub-horizontal, con un espesor aproximadamente de $1.50 \mathrm{~m}$.

En Guerrero, en la Región de la Montaña (parte nororiental del estado), se han reconocido siete áreas con evidencias de carbón en estratos del Jurásico Medio y Tardío (Corona-Esquivel, 1978). La zona con carbón, de Cualac en el Estado de Guerrero, es el área más promisoria. Se encuentra al norte de la población del mismo nombre y tiene una superficie de aproximadamente $80 \mathrm{~km}^{2}$. Los depósitos principales se encuentran en las cañadas de Cuachitzoloyo, Limontitlán y en la Loma La Viga, en la parte baja del Grupo Tecocoyunca de edad Jurásica. El carbón de esta área forma capas y lentes alargados, con espesores de pocos centímetros a $50 \mathrm{~cm}$ y excepcionalmente llegan a tener $80 \mathrm{~cm}$. El carbón encontrado hasta ahora es sucio, con impurezas de arcillas y valores de 4 al 17\% de carbón fijo (Corona-Esquivel, 1978).

La zona de Xalmolapa, Gro., también del Jurásico, tiene una superficie aproximada de $24 \mathrm{~km}^{2}$, se localiza al sureste de Cualac y norte de Tlapa; su litología es muy similar a la de Cualac, difiriendo en que los mantos de carbón tienen espesores menores a $50 \mathrm{~cm}$ y son mas lenticulares.

En la zona de Xixila, situada al noroeste de Olinalá, Gro., justo entre Xixila y Mitlancingo, sólo se encuentran capas gruesas de lutita carbonosa negra, con impresiones de plantas fósiles del Jurásico, y algunos fragmentos de troncos carbonizados, muy semejantes a los del arroyo de Cuachitzoloyo en la región de Cualac (Corona-Esquivel, 1978).

En la zona de Quechultenango, Gro., se encontraron pequeñas capas y lentes de carbón limpio, así como impresiones de tallos y troncos, contenidos en un estrato arenoso de edad Jurásico; estos lentes por su tamaño, no son de interés económico.

Las localidades potenciales de contener depósitos de carbón de edad Cretácico son: El Bolsón de Mapimí, en Durango; Temexalco, Cuxcatlán y Xilitla, en San Luis Potosí; Villa Pánuco en Veracruz; y Tancasneque en 
Tamaulipas. La información que se tiene de ellas es muy limitada (Salas y Benavides, 1976).

También existen localidades potenciales de depósitos de carbón de edad Cenozoico; entre ellas están: la Cuenca de Colombia en Nuevo León, que porta carbones subbituminosos de origen palustre de edad Eoceno, los de Yahualica y Chicontepec en Veracruz, de edad Oligoceno; los de Zacualtipan en Hidalgo, de edad miocénica, (cf. Cope, 1886; Ferrusquía-Villafranca, 1978; Castillo-Cerón et al., 1996); y los de Tamazuchale en San Luis Potosí, de edad terciaria.

Se conocen además algunas localidades con evidencias de lignito y/o turbas de origen lacustre, tales como Tehuichila y Zacualtipan y San Miguel Ocaxichitlán, Edo de Hidalgo, de edad Mioceno; y las de Chalco, Edo. de México, de edad Cuaternario.

Casi todas estas localidades carboníferas, sólo se conocen por estudios de reconocimiento; en muy poco casos se han efectuado trabajos de obra minera, Por ejemplo en Colombia, N.L., se produjo carbón para la Fundidora de Fierro y Acero de Monterrey, pero pronto se suspendió la producción por su bajo volumen; en Tecomatlán, Puebla, se trabajó en 1874 (Jiménez, 1921) una mina llamada "La Salvadora", pero su rendimiento escaso pronto obligó a cerrarla; otro tanto aconteció en la Peña de Ayuquila en el Estado de Puebla; por último, en 1875, se produjo carbón de la Mina "El Cristo 2," ubicada cerca Tempoal, Ver., mismo que era transportado por barco en el Río Pánuco, pero pronto se suspendió la producción por no ser costeable (Salas y Benavides, 1976).

\section{Conclusiones}

A pesar de que en México se conocen abundantes manifestaciones de carbón repartidas en series sedimentarias con edades comprendidas entre el Paleozoico y el Cuaternario, únicamente algunas cuencas carboníferas han podido ser desarrolladas tanto por el volumen de sus reservas como por la facilidad de su explotación.

Geográficamente, los principales yacimientos de este recurso natural se localizan en los estados de Coahuila, Oaxaca y Sonora. Entre ellas, la Región Carbonífera de Coahuila es la más importante del país, aportando más del $90 \%$ de la producción nacional de carbón. Este carbón explotable es de edad cretácica y aparece esencialmente en las "subcuencas" de Sabinas y de Esperanzas.

En general, el carbón de la sub-región "SabinasMonclova", es de tipo sub-bituminoso, apropiado para su transformación en coque, tiene volatilidad media a baja, presenta vitrinita preponderantemente como constituyente y un poder reflector de la vitrinita de 0.6-1.2\%. A diferencia del área anterior, en la sub-región "Zona de Fuentes-Río Escondido", el tipo de carbón es sub-bituminoso "C", de alta volatilidad (de flama larga), poco apropiado para que se le pueda transformar en coque, sin embargo esta siendo utilizado para la producción de energía eléctrica.

La cantidad y calidad del carbón contenidos en otras series mesozoicas fuera de las de Coahuila es variable, así como su importancia, siendo destacables los yacimientos de San Marcial-Sta Clara y Cabullona en el Estado de Sonora así como Corralitos en Chihuaha.

En la porción sur del país, el carbón contenido en las secuencias jurásicas de la región Tezoatlan-Mixtepec en el Estado de Oaxaca, constituyen una reserva confiable que pudiese ser aprovechada a corto plazo para la generación de energía eléctrica.

Los indicios de carbón que aparecen en series paleozoicas, como los de las formaciones Matzitzi en Puebla y Los Arcos en Guerrero, tienen pocas posibilidades de contener depósitos económicamente explotables, por otra parte estos presentan un mayor grado de dificultad para su explotación debido a que por lo general están mas deformados.

No quisiéramos concluir sin aludir a la problemática del metano en las cuencas carboníferas, sobretodo en lo que hace a su posible aprovechamiento como fuente de energia de bajo costo. El metano o gas grisú es y ha sido un problema grave en la explotación de los cuerpos de carbón, debido tanto a su toxicidad como a su gran riesgo de explosión. Una de las posibilidades que se han manejado es el "drenado" de dicho gas previo a la explotación de los mantos de carbón, o su explotación "a posteriori” una vez abandonada la mina. Las cantidades de metano generadas no son suficientes en general como para su explotación comercial a gran escala, aunque si que lo son como fuente local, alternativa y barata de energía para la generación de electricidad dedicada tanto a la industria local (ya hasta para la misma minería) como para las poblaciones localizadas en sus cercanías. En épocas recientes, la ley que en México rige la explotación de hidrocarburos no permitía que otra compañía que no sea Pemex pueda explotar dichos recursos, aunque a esta última no le interese en absoluto la explotación a pequeña escala de recursos que, de otra forma, se están liberando a la atmósfera. Esta liberación incontrolada de gases de efecto invernadero, dentro de los cuales se cuenta el metano, origina que México en estos momentos sea un país contaminador neto y que, a la vez, se esté malgastando un precioso recurso energético que podría aportar riqueza económica suplementaria a ciertas zonas del país. Es de destacar que las estimaciones de producción de gas a partir de los carbones de las subcuencas Sabinas y Saltillito, $1.22 \cdot 10^{11}$ y $2.2 \cdot 10^{11} \mathrm{~m}^{3}$ respectivamente, son lo suficientemente importantes a nivel local como para que se les de un uso industrial o doméstico.

\section{Agradecimientos}

El presente estudio fue financiado por la Universidad Nacional Autónoma de México, (Instituto de Geología y Centro de Geociencias, Campus Juriquilla). Muy especialmente se agradece a los doctores Enrique Martínez 
Hernández y Gilles Levresse por sus comentarios y apoyo para mejorar este artículo.De igual forma, el primer y tercer autor expresan su agradecimiento al Consejo de Recursos Minerales y a la compañía Minera Carbonífera Río Escondido (MICARE), por permitir la publicación de los datos obtenidos durante los trabajos de exploración realizados para esas instituciones. Finalmente Piedad-Sánchez agradece a CONACyT y PROMEP (UACOAH-PTC-073) por su apoyo para la realización de este trabajo.

\section{Referencias bibliográficas}

Águeda, J.A., Bahamonde, J.R., Barba, F.J., Barba, P., Colmenero, J.R., Fernández, L.P., Salvador, C.I., Vera, C., 1991, Depositional environments in Westphalian coal-bearing successions of the Cantabrian Mountains, northwest Spain, en: Bertrand, P. (Editor), Coal: Formation, occurrence and related properties, Bulletin de la Société Géologique de France 162, 325-333.

Alencáster, G., 1961, Fauna fósil de la Formación Santa Clara (Cárnico), Paleontología Mexicana 11, Parte III, pp 1-44.

Bodden, R.W. III, Ehrlich, R., 1998, Permeability of coals and characteristics of desorption tests: Implications for coalbed methane production: International Journal of Coal Geology 35, 333-347.

Böse, E. y Cavins, O. A., 1927, The Cretaceous and Tertiary of southern Texas and northen Mexico: Texas University Bulletin, 2748, p. $7-142$.

Brizuela, V.L., 1992, Geología General de la zona Carbonífera de Monclova-Sabinas, Estado de Coahuila: Minerales Monclova S.A. de C.V. Tomo I, $74 \mathrm{p}$.

Bustin, R.M., Clarkson, C.R., 1998, Geological controls on coalbed methane reservoir capacity and gas conten: International Journal of Coal Geology, 38, 3-26.

Calder, J.H., Gibling, M.R., Mukhopadhyay, P.K., 1991, Peat formation in a Westphalian B piedmont setting, Cumberland basin, Nova Scotia: implications for the maceral-based interpretation of rheotropic and raised paleomires: Bulletin de la Société Géologique de France, $162,283-298$.

Calderón-García, A., 1956, Estratigrafía del Mesozoico y tectónica del sur del Estado de Puebla: Congreso Geológico Internacional: México, D. F., 20, Excursión, A-11, p. 9-27.

Castillo-Cerón, J. M., Cabral-Perdomo, M. A. y Carranza-Castañeda, O., 1996, Vertebrados fósiles del Estado de Hidalgo. Pachuca, Hgo.: Universidad Autónoma del Estado de Hidalgo, México, Publicación Especial, 127 pp.

Chen P., Ma J., 2002. Petrographic characteristics of Chinese coals and their application in coal utilization processes: Fuel, 81, 1389-1395.

Clayton, J.L., 1998. Geochemistry of coalbed gas - A review: International Journal of Coal Geology, 35, 159-173.

Consejo de Recursos Minerales, 1994, Monografía Geológico-Minera del Estado de Sonora: México D.F., México, 220 p.

Consejo de Recursos Minerales, 1996, Monografía Geológico-Minera del Estado de Oaxaca: México D.F., México, 280 p.

Cope, E. D., 1886, Report in the coal deposits near Zacualtipan, in the State of Hidalgo, Mexico: American Philosophical Society, 23, p. 146.151 .

Corona-Esquivel, R., 1978, Estudio Geológico de los depósitos carboníferos de la porción noreste del Estado de Guerrero: México, D. F., Consejo de Recursos Minerales (informe inédito).

Corona-Esquivel, R., 1981 (1983), Estratigrafía de la región comprendida entre Olinalá y Tecocoyunca, noreste del estado de Guerrero: Universidad Nacional Autónoma de México, Instituto de Geología, v.5, p. 17-24.

Corona-Esquivel, R., Silva-Pineda A., Morales-Isunza A., 1995, Estratigrafía y flórula jurásica del Cerro "El Temichi”, Municipio de Acaxtlahuacán, Estado de Puebla, México: Revista de la Sociedad
Mexicana de Paleontología, 8, 25-40.

Cortés-Obregón, S., Torón, V. L., Martínez-Bermúdez, J.. J., Pérez-Larios, J., Gamboa, A. J., Cruz, C. A., y Puebla, P. M., 1957, La Cuenca carbonífera de la Mixteca: México, D. F., Banco de México, S. A., Vol. 1, 191 pp, Vol. II, 66 pp.

Crosdale, P.J., Basil, Beamish, B., Valix, M., 1998, Coalbed methane sorption related to coal composition: International Journal of Coal Geology 35, 147-158.

Diessel, C.F.K., 1986, On the correlation between coal facies and depositional environments. Advances in the study of the Sydney basin: Newcastle, Australia, 20 Newcastle Symposium Proceedings. University of Newcastle, 19-22.

Diessel, C.F.K., 1992. Coal-bearing depositional systems: Berlín, Springer, $721 \mathrm{p}$.

Dumble, E.T. 1899, Notes on the Geology of Sonora: Institute Mining Engineers. Transactions A. M. Vol XXIX.

Dumble, E.T., 1892, Notes on the geology of the Valley of the Middle Rio Grande: Geological Society of America Bulletin, 3, 219-230.

Eguiluz de Antuñano, S., 2001, Geologic evolution and gas resources of the Sabinas basin in northeastern Mexico, en: Bartolini, C., Bufler, R.T., Cantú-Chapa, A. (Eds.), The western Gulf of Mexico Basin: tectonics, sedimentary basins and petroleum systems: AAPG Memoir 75, 241-270.

Erben, Heinrich K., 1956a, El Jurásico Inferior de México y sus amonitas: México, Congreso Geológico Internacional, XX Sesión, 393 p.

Erben, Heinrich K., 1956b, El Jurásico Medio y el Calloviano de México: México, Congreso Geológico Internacional, XX Sesión, 140 p.

Ferrusquía-Villafranca, I., 1978, Distribution of Cenozoic vertebrate faunas and problems of migration between North and South America, pp 193-321; en Conexiones terrestres entre Norte y Sudamerica: Simposio interdiciplinario sobre Paleogeografía Mesoamericana: Boletín del Instituto de Geología de la UNAM, 101.

Flores, T., 1930, Reconocimientos geológicos en la región central del estado de Sonora: Boletín del Instituto de Geología de la UNAM, $49,267 \mathrm{p}$.

Flores, R.M., 1998, Coalbed methane: From hazard to resource: International Journal of Coal Geology, 35, 3-26.

Flores-Espinoza, E., 1989. Stratigraphy and sedimentology of the Upper Cretaceous terrigenous rocks and coal of the Sabinas-Monclova area, Northern Mexico:Austin, Texas, Tesis de Doctorado, 315 p.

Flores-Galicia, E.,1988, Geología y reservas de los yacimientos de carbón en la República Mexicana, en Salas, G.P. (Ed.) Geología de México: México, Fondo de Cultura Económica, 175-217 p.

Gobierno del Estado de Coahuila, 2003, Programa regional de competitividad sistémica: Coahuila competitivo 2020: Coahuila, Secretaría de Economía, Gobierno del estado de Coahuila de Zaragoza, pp. 167-182.

Gobierno del Estado de Coahuila, 2005, Prontuario de indicadores socioeconómicos. Secretaría de Desarrollo: Coahuila, Gobierno del estado de Coahuila de Zaragoza, pp. 14-16.

Imlay, R. W., 1937, Stratigraphy and paleontology of the Upper Cretaceous beds along the eastern side of Laguna de Mayran, Coah., México: Geological Society of America Bulletin, 48 (12), 1785-1872.

Jiménez, L. G., 1921, El carbón Mineral en México: Boletín Minero, Tomo XI, 5, 650-709.

King R. E., 1939, Geological Reconnaissance in Northern Sierra Madre Occidental of Mexico, Geological Society of America. Vol. 50.

Krooss, B.M., Van Bergen, F., Gensterblum, Y., Siemons, N., Pagnier, H.J.M., David, P., 2002, High-pressure methane and carbon dioxide adsorption on dry and moisture-equilibrated Pennsylvanian coals: International Journal of Coal Geology, 51, 69-92.

Laherrère, J., 2000, Quelles énergies en 2020 et quelles incertitudes?: Géologues, Revue Officielle de l'Union Française des Géologues, 124, 31-44.

Laxminarayana, C., Crosdale, P.J., 1999, Role of coal type and rank on methane sorption characteristics of Bowen Basin, Australia coals: International Journal of Coal Geology 40, 309-325.

López-Ramos, E., 1985, Geología de México: Tomo II. 3a edition, Mexico, $454 \mathrm{p}$.

Micare, 1982, Carbón mineral y electricidad en México: Dirección de 
Relaciones Publicas MICARE (Minera Carbonifera Río Escondido), Publicación Especial, 54p.

Mukhopadhyay, P.K., Hatcher, P.G., 1993, Composition of coal, in Law, B.E., Rice, D.D., (eds.), Hydrocarbons from coal: AAPG, Studies in Geology, 38, 79-113.

Mullerried, F. K. G., 1941, Actividad volcánica bastante reciente del oriente del estado de Coahuila, México: Revista Geográfica del Instituto Panamericano de Geografía e Historia, Tomo I, 2-3, 183-201.

Ojeda-Rivera, J., 1975, Revaluación Geoeconómica de los dépositos de Carbón del area de Tezoatlan Oaxaca: Geomimet, 79, 18p.

Philp, R.P., 1994, Geochemical characteristics of oils derived predominantly from terrigenous source materials, en Scott, A.C., Fleet, A.J. (eds.) Coal and coal-bearing strata as oil-prone source rocks? The Geological Society of London Special Publication, 77, 71-91.

Piedad-Sánchez, N., 2005, Estudio de la Industria del Carbón en la Región Carbonífera del Estado de Coahuila y del cluster del carbón a nivel mundial: Corporación Mexicana de Investigación en Materiales, S.A., pp. 16-29.

Piedad-Sánchez, Noé., Martinez, Luís., Suárez-Ruiz, Isabel., Alsaab, Dani., Izart, Alain., Milenkova, Katia., 2005, Estudio preliminar de la estructura del carbón de la Formación Olmos en la Región Carbonífera, Coahuila, México: Convención Internacional de Minería XXVI. Veracruz, Ver. Acta de Sesiones, p. 89-90.

Prothero, D. R. y Schwab F., 1996, Sedimentary Geology, an Introduction to Sedimentary Rocks and Stratigraphy: New York, W.H. Freeman and Company, $575 \mathrm{p}$.

Querol Suñé Francisco, 2005, desperdicio del gas grisú en México. Asociación de Ingenieros de Minas, Metalurgíasta y Geólogos de México, A.C., Convención Internacional de Minería XXVI. Veracrúz, Ver. Acta de Sesiones, p. 461-465.

Raisz, E., 1959, Landforms of Mexico: Cambridge, Mass., U.S. Navy Geographical Branch, mapa, escala 1:3'000,000.

Rangin, C., 1978, Speculative model of Mesozoic geodynamics, Central Baja California to northeastern Sonora, México, en Howelle, D. C. y McDougall, K. A., (eds.), Mesozoic paleogeography of the western United States: Los Angeles, California, Soc. Econ. Paleont. Miner., 2nd. Pacific Coast Symposium, 85-105

Rivera-Martínez, J. C., y Alcocer-Valdés C., 2003, La situación actual del aprovechamiento del carbón en el estado de Coahuila: Boletín Técnico del Consejo de Recursos Minerales, IX, 54. 2-19.

Robeck R. C., Pesquera V. Rubén y Ulloa A. S., 1956, Geología y depósitos de carbón de la región de Sabinas, Estado de Coahuila, en XX Congreso Geológico Internacional: México, 109 p.

Robeck, R.C., Pesquera R.V., Ulloa S.A., 1960.Geología y depósitos de carbón de la región de Sabinas, Estado de Coahuila, in Sociedad Geológica Mexicana (ed.), Libreto guía de la excursión C-3 del XX Congreso Geológico Internacional: Geología a lo largo de la carretera entre el D.F. y Saltillo, Coah. Distritos mineros de Guanajuato y Ávalos Concepción del Oro - Mazapil, Zac. Minas de carbón de Monclova y Nueva Rosita, Coah., 87-115.

Roldán-Quintana, J., 1984, Evolución tectónica del Estado de Sonora: Revista del Instituto de Geologia de la UNAM, 5, 178-185.

Román-Ramos, J.R., Holguín-Quiñones, N., 2001, Subsistemas generadores de la región norte de Mexico: Boletín de la Asociación Mexicana Geólogos Petroleros, 49, 68-84.

Salas, G., Benavides, L., 1976, La exploración y las reservas mexicanas de carbón. Instituto Latinoamericano del Fierro y el Acero (ILAFA), en Congreso: Usos del carbón en siderurgia: abastecimiento y tecnologías: México DF, 79-90.
Santamaría-Orozco, D.M., 1990, Ambientes sedimentarios de las rocas del Cretácico Superior en la Cuenca Carbonífera de Sabinas, Estado de Coahuila, México: Facultad de Ingeniería, Universidad Nacional Autónoma de México, Tesis de Maestría, 72 p.

Servicio Geológico Mexicano, 2003. Anuario estadístico de la minería mexicana. $479 \mathrm{p}$.

Silva-Pineda, A., 1969, Plantas fósiles del Jurásico Medio de Tecomatlán, Estado de Puebla: Universidad Nacional Autónoma de México, Instituto de Geología, Paleontología Mexicana 27, Parte I, p. $1-76$.

Silva-Pineda, A., 1978, Plantas del Jurásico Medio del Sur de Puebla y Noroeste de Oaxaca: Universidad Nacional Autónoma de México, Instituto de Geolología, Paleontología Mexicana 44, Parte III, pp $1-44$.

Silva-Pineda, A., 1984, Revisión taxonómica y tipificación de las plantas jurásicas colectadas y estudiadas por Wieland (1914) en la región de El Consuelo, Oaxaca: Universidad Nacional Autónoma de México, Instituto de Geolología, Paleontología Mexicana 49, pp 1-112.

Stephenson, L.W.,1927, Notes on the Stratigraphy of the Upper Cretaceous formations of Texas and Arkansas: Am. Assoc. Petroleum Geologist Bull., Vol. 11, No. 1, 1927, p. 1-17.

Tissot, B., 2001, Quel avenir pour les combustibles fossiles? Energies et climat. Comptes Rendus de l'Académie des Sciences 333, 787-796.

Van Krevelen, D.W., 1993. Coal: typology, chemistry, physics, constitution. Industrial Chemistry Petroleum and Fuel Technology. 3rd edition. Elsevier Publisher. Arnhem, The Netherlands, $1000 \mathrm{p}$.

Vaughan, T. W., 1900, Reconnaissance in the Rio Grande coal fields of Texas: U.S. Geol. Survey Bull. 164.

Verdugo D.F., Ariciaga M.C., 1988a, Informe Geológico de la cuenca carbonífera Fuentes-Río Escondido Coahuila.: in Fondo de Cultura Económica, S.A. de C.V., Geología Económica de México, (Salas ed.). p. 143-170.

Verdugo, D.F., Ariciaga, M.C., 1988b. Resumen de la exploración y explotación en Río Escondido. In: Salas G. (Editor): Geología Económica de México. Fondo de Cultura Económica. México, pp. 171-174.

Wieland, G. R., 1914, La flora liásica de la Mixteca Alta: Instituto de Geología. México, Bol. 31, 165 pp y 50 láms.

Wilkins R.W.T., George S.C., 2002. Coal as a source rock for oil: a review. International Journal of Coal Geology 50, 317-361.

Wilson I. F., Rocha V.S., 1946, Los Yacimientos de Carbón de la Región de Santa Clara,Municipio de San Javier, Estado de Sonora: Comite Directivo para la Investigación de los Recursos Minerales de México Boletin Núm. 9. 108p

Young, K., 1972. Cretaceous Paleogeography: Implications of Endemic Ammonite Faunas. Bureau of Economic Geology, University of Texas, Geological Circular 72, 2.

Young, K., 1983. Mesozoic history of Mexico. In: Moullade, M., Narm, A.E.M. (Editores), The Phanerozoic geology of the world 2, B

Manuscrito recibido: Noviembre 6, 2005

Manuscrito corregido recibido: Marzo 16, 2006

Manuscrito aceptado: Junio 27, 2006 